Research article

\title{
Border control for stowaway alien species should be prioritised based on variations in establishment debt
}

\author{
Katelyn T. Faulkner a, b, *, Mark P. Robertson ${ }^{b}$, Mathieu Rouget ${ }^{\mathrm{c}}$, John R.U. Wilson ${ }^{\text {a, }}$, \\ a Invasive Species Programme, South African National Biodiversity Institute, Kirstenbosch Research Centre, Private Bag X7, Claremont, 7735, South Africa \\ ${ }^{\mathrm{b}}$ Centre for Invasion Biology, Department of Zoology and Entomology, University of Pretoria, Hatfield, 0028, South Africa

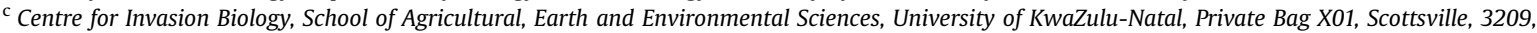 \\ South Africa \\ d Centre for Invasion Biology, Department of Botany and Zoology, Stellenbosch University, Private Bag X1, Matieland, 7602, South Africa
}

\section{A R T I C L E I N F O}

\section{Article history:}

Received 9 December 2015

Received in revised form

26 April 2016

Accepted 9 May 2016

\section{Keywords:}

Biological invasion

Prioritised inspection strategies

Border control

Climatic similarity

Resource allocation

Inspection effort

\begin{abstract}
A B S T R A C T
Border control is one of the major approaches used by countries to limit the number of organisms introduced as stowaways. However, it is not feasible to inspect all passengers, cargo and vehicles entering a country, and so efforts need to be prioritised. Here we use South Africa as a case study to assess, based on tourism and trade data and climate matching techniques, the number of stowaway species that might be introduced ('colonisation pressure') and the likelihood that once introduced, these organisms will establish ('likelihood of establishment'). These results were used to explore how the number of species that are likely to establish ('establishment debt') varies across donor regions and seasons. A simple theoretical model was then used to compare four strategies for prioritising border control inspections: no prioritisation; based on colonisation pressure; based on likelihood of establishment; and based on both colonisation pressure and likelihood of establishment. Establishment debt was greatest in southern hemisphere spring and autumn when South Africa is climatically similar to northern hemisphere countries with which there are strong, consistent trade and tourism links (i.e. colonisation pressure varied little seasonally, but likelihood of establishment did vary across the seasons). Prioritising inspections based on both colonisation pressure and the likelihood of establishment was clearly the most effective strategy, with this strategy detecting at least $6 \%$ more potential invaders than the other strategies. While there are many practical limitations to the implementation of such prioritised inspection strategies, the results highlight the importance of national and regional studies of establishment debt.
\end{abstract}

(C) 2016 Elsevier Ltd. All rights reserved.

\section{Introduction}

The movement of goods and people around the globe is increasing, leading to an increase in the introduction of organisms to regions where they are not native (Levine and D'Antonio, 2003; Westphal et al., 2008). Organisms are often unintentionally introduced as stowaways on or in transport vectors (Hulme et al., 2008). Some of these stowaway organisms become invasive and have undesirable ecological and economic impacts (Pimentel et al., 2001; Simberloff et al., 2013). Where an effort is made to prevent these unintentional introductions, likely vectors (e.g. goods, traveller's luggage and vehicles) are identified and inspected at the

\footnotetext{
* Corresponding author. Centre for Invasion Biology, Department of Zoology and Entomology, University of Pretoria, Hatfield, 0028, South Africa

E-mail address: katelynfaulkner@gmail.com (K.T. Faulkner).
}

border.

Inspection services, however, face many obstacles and while the number of vectors requiring inspection has increased (Bacon et al., 2012; McCullough et al., 2006), the resources available for these inspections (budget and personnel) are limited (Simberloff, 2006). Consequently, only a small proportion of the potential vectors can actually be inspected (Bacon et al., 2012; McCullough et al., 2006) and a large number of organisms go undetected (Stanaway et al., 2001; Work et al., 2005). Inspection services also often only target agricultural pests, neglecting organisms that will have environmental impacts (Bacon et al., 2012). The development and implementation of prioritised inspection strategies could improve this situation and, if based on underlying risks or the potential costs of pest introduction, could result in more efficient and effective border control (Areal et al., 2008; Bacon et al., 2012; Surkov et al., 2008). Unfortunately evaluations tend to be at a global 
scale-there has been little effort to link evaluations of the underlying risks to prevention strategies at regional scales (but see Bacon et al., 2012; Keller et al., 2011; Macisaac et al., 2002).

Attempts to consider the underlying risks have largely focused on the likelihood that organisms will be introduced from one region to another (e.g. Bacon et al., 2012; Drake and Lodge, 2004; Maclsaac et al., 2002). As the number of organisms that are introduced is rarely known with accuracy, these endeavours use proxies (e.g. the number of people or goods transported) that are positively correlated with the likelihood of introduction (Drake and Lodge, 2004; Liebhold et al., 2006; Tatem et al., 2006a). Such research has proposed that prevention strategies should prioritise vectors traveling from regions from which a large number of organisms are introduced. However, this approach neglects two potentially important factors that may have consequences for the efficient allocation of resources. Firstly, the number of organisms introduced is likely to change over time (e.g. increasing during the peak tourism season; Tatem and Hay, 2007). Secondly, introduced organisms need to be able to establish in order to become invasive, and the likelihood of establishment will vary spatially and seasonally. To establish, an introduced organism must survive in the recipient environment upon introduction and thus the donor and recipient regions must be sufficiently climatically similar. The higher the climatic similarity the higher the likelihood that an introduced organism will establish (Andow, 2003). For stowaway organisms that are sensitive to small changes in climate (e.g. arthropods and micro-organisms, referred to here as 'climatically sensitive organisms') this might be a substantial barrier to invasion, with establishment only possible during seasons when the donor and recipient environments have a high climate match. Due to these two factors, the number of alien species that are introduced and establish should vary across donor regions and over time, and will be greatest during periods of the year when the number of introductions and the likelihood of establishment are highest (Tatem and Hay, 2007).

As developing countries have few resources available for border control (Mumford, 2002), inspection strategies need to be effectively prioritised, requiring national-level assessments of underlying risks. Here, South Africa is used as a case study to evaluate the risk of invasion posed to natural and semi-natural environments by climatically sensitive organisms that are introduced as stowaways. As a country that relies heavily on imports, South Africa should be particularly at risk of such invasions (Tatem, 2009) and in line with this there has been a recent increase in the number of established arthropods (Giliomee, 2011). Our aim was to explore how the number of species that could be introduced and establish in a region varies across donor regions and seasons, and to assess the implication of any variation when developing inspection strategies.

\section{Materials and methods}

The number of species that are likely to establish in South Africa (referred to as 'establishment debt' (Rouget et al., 2016)) was assessed by taking into account two key stages of the invasion continuum (i.e. introduction and establishment (Blackburn et al., 2011)). For each season the number of stowaway species that would be introduced from a foreign country to South Africa was assessed, and the likelihood that these species would establish was evaluated. These results were combined to determine how establishment debt varies seasonally and how donor regions vary in their contribution to this debt. In this paper, colonisation pressure refers to the number of species introduced (Lockwood et al., 2009), and the likelihood of establishment is the likelihood that a species will be introduced to an area with a suitable climate and establish. Note, the eventual impact of the species is not considered here (see supplementary materials for the full methodology).

\subsection{Colonisation pressure}

Trade and tourism data were used as a proxy for colonisation pressure. Monthly country-level data on the number of foreign tourists and the value of commodity imports (in South African Rand) were obtained from Statistics South Africa and the South African Department of Trade and Industry for 2007 to 2011. These data were used to determine the monthly colonisation pressure posed by each foreign country to South Africa. Let $j \in M$, where $M$ is the set of months of the year, and let $H_{j}$ be average tourism and $W_{j}$ be average imports for month $j$. The monthly colonisation pressure posed by each country was calculated using the formula below which weighted tourism and imports equally:

$M_{j}=\frac{1}{2}\left(\frac{H_{j}}{\sum_{i \in M} H_{i}}+\frac{W_{j}}{\sum_{i \in M} W_{i}}\right)$

Seasonal results were obtained by averaging across months that fall into southern hemisphere seasons (i.e. winter is June-August; spring is September-November etc.). The relative seasonal colonisation pressure posed by each country was designated as low, medium or high (colonisation pressures greater than or equal to the 75th percentile were high; greater than or equal to the 50th percentile were medium; and the remainder were low).

\subsection{Likelihood of establishment}

The likelihood that organisms introduced from foreign countries could establish in South Africa (given that they had survived transportation and were introduced) was assessed using two climate matching techniques. The climatic similarity between South Africa and foreign countries was firstly evaluated at a city level using a point-based technique, and secondly at a country level using a grid-based method. The two climate matching techniques measured the likelihood of different extents of establishment. The point-based technique measured the likelihood that introduced organisms will survive and reproduce at the point of introduction, while the grid-based method measured the likelihood that introduced organisms will survive and reproduce a significant distance from the point of introduction. The results of the two methods were then combined to obtain a measure of likelihood of establishment.

\subsubsection{Point-based climate matching technique}

Gridded monthly mean temperature and precipitation data from the CRU CL 2.0 dataset at a spatial resolution of $10 \mathrm{~min}$ (New et al., 2002) were used to calculate the monthly climatic distance between large South African and large foreign cities (organisms are often transported between large cities; for example, mosquitos most often enter New Zealand through Auckland (Derraik, 2004)). As recommended by Bradie et al. (2015) unweighted Euclidean distance was calculated following standard methods (Barry et al., 2008) using the 'stats' package in R (R Core Team, 2013) (see Figs S1-S4 in supplementary materials for examples of pairwisecomparison results). Seasonal, pairwise results were obtained by averaging the Euclidean distance values for months that fall into southern hemisphere seasons. For each season, the Euclidean distance value from the city in each country that is the most climatically similar to a South African city (i.e. that with the lowest Euclidean distance) was utilised as a measure of climatic similarity between the two countries. This value represents the maximum likelihood that an organism transported from a foreign country to South Africa will find a suitable climate at the point of introduction. For each season, countries were designated as having a low, 
medium or high climatic similarity to South Africa. As low Euclidean distance values indicate high climatic similarity, countries with values less than or equal to the 25 th percentile had a high climatic similarity, those with values less than or equal to the 50th percentile had a medium climatic similarity, and the remainder had a low climatic similarity (see Fig. S5 for a schematic diagram demonstrating the steps followed during point-based climate matching).

\subsubsection{Grid-based climate matching technique}

We used the biome climate matching method presented in Faulkner et al. (2014), which employs the BIOCLIM method (Busby, 1991), and gridded monthly mean precipitation and temperature data (New et al., 2002) to identify, for each month, regions of the world with similar climates to the South African biomes (based on the classification of Olson et al., 2001). For each month the maximum predicted value for each cell was used and each cell was assigned a value of 1 if climatically similar to South Africa (all predicted cells: percentiles 0 to 100) or 0 if not climatically similar to South Africa. Monthly country level results were obtained by calculating the number of grid cells that are climatically similar to South Africa. The average number of grid cells that are climatically similar to South Africa for each season was calculated, and the countries that have a low, medium or high climatic similarity were identified using the thresholds detailed in Section 2.1.

\subsubsection{Combining point- and grid-based measures of climatic similarity}

For each country the point- and grid-based climate matching method results were combined to obtain a seasonal measure of likelihood of establishment. Following a precautionary approach, the likelihood of establishment was the highest level of climatic similarity assigned for each season (for example, if a country's climatic similarity was medium for the point-based method and high for the grid-based method then the likelihood of establishment was high). This rule was applied except when a country had a high climatic similarity for the point-based method and a low climatic similarity for the grid-based method. In such instances, an organism has a high likelihood of establishing at the point of introduction but will not establish widely (unless environmental conditions change) and thus a medium likelihood of establishment was assigned.

\subsection{Establishment debt}

Establishment debt (i.e. the number of introduced species that will establish over a given time horizon (Rouget et al., 2016)) is calculated as the product of colonisation pressure (i.e. the number of species introduced (Lockwood et al., 2009)) and the likelihood of establishment. Accordingly, for each season, if both colonisation pressure and the likelihood of establishment are high then a given country will contribute a high number of species to South Africa's establishment debt; if either colonisation pressure or the likelihood of establishment are low then the country contributes a low number of species to the establishment debt; and if either component is medium and neither low, then the country will contribute a medium number of species to the debt. The thresholds used to assign levels of establishment debt contribution were standardised by identifying the season (in this case winter) with the greatest number of countries that contribute a high number of species to establishment debt and then using the percentiles for this season to determine establishment debt contribution for all seasons.

Results were mapped using the R package 'maptools' (Bivand and Lewin-Koh, 2013), and the number of countries that contribute a low, medium or high number of species to establishment debt was determined. The percentage of countries for which there was a mismatch between colonisation pressure and likelihood of establishment (i.e. high colonisation pressure but low likelihood of establishment or vice versa) was also calculated. Plotting and analyses were performed in R (R Core Team, 2013).

\subsection{Theoretical model}

\subsubsection{Model concept}

A simple theoretical model was developed to evaluate four inspection strategies: (1) inspections with no prioritisation, (2) inspections prioritised based on colonisation pressure, (3) inspections prioritised based on likelihood of establishment, (4) inspections prioritised based on establishment debt (for details see Section 2.4.3). The model took into account the stages of the invasion process, and the inspection strategies were evaluated using four criteria: (1) the total number of species detected (referred to here as 'total number of detections'), (2) the number of species detected that will establish ('total number of detected establishers'), (3) efficacy ('strategy efficacy') and (4) effort (see Sections 2.4.2 and 2.4.3). The model is based on the premise (shown in Fig. 1) that of the species that are transported to a region, a proportion will not survive transportation ('transport casualties'). Of those that do survive transportation ('transport survivors'), a proportion will fail to establish ('establishment failures') due to an unsuitable climate and a proportion, for which the climate is suitable, will establish ('establishers'). Additionally, if border control is implemented a proportion of the transported species will be detected (hatched sections of Fig. 1). Of the total number of species detected, some will be transport casualties ('detected casualties'), some will be establishment failures ('detected failures') and some will be establishers ('detected establishers').

\subsubsection{Model}

The model components and notation are detailed in Table 1. It was assumed for simplicity that each recipient-donor country combination refers to a route $v$. Let $v \in V$, where $V$ is a set of routes. A number of species $T_{v}$ are transported along each route $v$ (Fig. 1). For each route the number of detections $D_{v}$ is the sum of the number of detected casualties $\tilde{D}_{v}$, detected failures $\bar{D}_{v}$ and detected establishers $\widehat{D}_{v}$, therefore $D_{v}=\tilde{D}_{v}+\bar{D}_{v}+\widehat{D}_{v}$. The number of detected casualties $\tilde{D}_{v}$ is determined by the number of transport casualties $C_{v}$ and the probability of detection $P_{v}$, thus $\tilde{D}_{v}=C_{v} \times P_{v}$. The number of transport casualties $C_{v}$ is the difference between the number of transported species $T_{v}$ and the number of transport

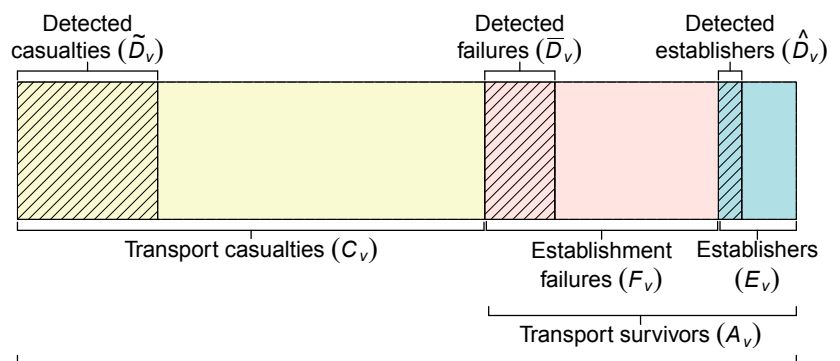

Number of species transported $\left(T_{v}\right)$

Fig. 1. The premise behind the theoretical model used to evaluate four inspection strategies for border control. Of the number of species transported $T_{v}$ along a route $v$ from a donor country to a recipient country, some species will not survive transportation $C_{v}$. Of those species that will survive transportation $A_{v}$, some will fail to establish $F_{v}$ and some will establish $E_{v}$. A proportion of these species will be detected by inspection services (hatched sections). 
Table 1

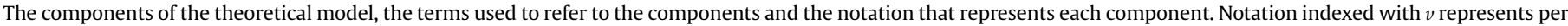
route quantities and that indexed with $s$ represents per inspection strategy quantities. Probabilities are denoted by $P$.

\begin{tabular}{|c|c|c|}
\hline Notation & Term & Model component \\
\hline$T_{v}$ & Number of species transported & Number of species transported along each route \\
\hline$C_{v}$ & Transport casualties & Number of species that do not survive transport along each route \\
\hline$A_{v}$ & Transport survivors & Number of species that survive transport along each route \\
\hline$F_{v}$ & Establishment failures & Number of species transported along each route that survive transport but fail to establish \\
\hline$E_{v}$ & Establishers & Number of species transported along each route that survive transport and that will establish \\
\hline$D_{v}$ & Number of detections & Number of species transported along each route that are detected by inspection services \\
\hline$\tilde{D}_{v}$ & Detected casualties & Number of detected species transported along each route that do not survive transport \\
\hline $\bar{D}_{v}$ & Detected failures & Number of detected species transported along each route that survive transport but fail to establish \\
\hline$\widehat{D}_{v}$ & Detected establishers & Number of detected species transported along each route that survive transport and establish \\
\hline$I_{v}$ & Inspection effort & Inspection effort allocated to each route \\
\hline$\widehat{I}_{v}$ & Effort per establisher & Inspection effort allocated to each route to detect each establisher \\
\hline$\overline{\bar{P}}_{v}$ & Probability of surviving transport & Probability that a species transported along a route survives transport \\
\hline $\bar{P}_{v}$ & Probability of establishment failure & Probability that a species transported along a route fails to establish \\
\hline$P_{v}$ & Probability of detection & Probability that a species transported along a route is detected \\
\hline$D_{s}$ & Total number of detections & Number of species detected for each strategy \\
\hline$\widehat{D}_{s}$ & Total number of detected establishers & Number of species detected for each strategy that will survive transport and establish \\
\hline$E_{S}$ & Strategy efficacy & The efficacy of each strategy \\
\hline$\widehat{I}_{S}$ & Effort & Average inspection effort allocated in each strategy to detect each establisher \\
\hline
\end{tabular}

survivors $A_{v}$, therefore we have $C_{v}=T_{v}-A_{v}$. Where the number of transport survivors $A_{v}$ is determined by the number of transported species $T_{v}$ and the probability of surviving transport $\overline{\bar{P}}_{v}$, thus $A_{V}=T_{v} \times \overline{\overline{P_{v}}}$. The number of detected failures $\bar{D}_{v}$ is determined by the number of establishment failures $F_{v}$ and the probability of detection $P_{v}$, therefore $\bar{D}_{v}=F_{v} \times P_{v}$. The number of establishment failures $F_{v}$ is determined by the number of transport survivors $A_{v}$ and the probability of establishment failure $\bar{P}_{v}$, therefore $F_{v}=A_{v} \times \bar{P}_{v}$. The number of detected establishers $\widehat{D}_{v}$ is determined by the number of establishers $E_{v}$ and the probability of detection $P_{v}$, therefore we have $\widehat{D}_{v}=E_{v} \times P_{v}$. The number of establishers $E_{v}$ is the difference between the number of transported species $T_{v}$, the number of transport casualties $C_{v}$ and the number of establishment failures $F_{v}$, thus $E_{v}=T_{v}-\left(C_{v}+F_{v}\right)$. Let $s \in S$, where $S$ is a set of inspection strategies. The total number of detections for each inspection strategy $D_{s}$ is the number of detections across all routes, therefore $D_{s}=\sum_{k \in V} D_{v}$. The total number of detected establishers for each inspection strategy $\widehat{D}_{s}$ is the number of detected establishers $\widehat{D}_{v}$ across all routes, therefore we have $\widehat{D}_{s}=\sum_{k \in V} \widehat{D}_{v}$. Inspection strategy efficacy $E_{S}$ is the percentage of establishers detected across all routes, thus $E_{S}=100\left(\frac{\sum_{k \in V} \widehat{D}_{v}}{\sum_{k \in V} E_{v}}\right)$. For each route, effort per establisher $\widehat{I}_{v}$ is the proportion of inspection effort $I_{v}$ allocated to detect each establisher $E_{v}$, therefore $\widehat{I}_{v}=\frac{I_{v}}{E_{v}}$. For each inspection strategy, effort $\widehat{I}_{S}$ is the average effort per establisher across routes, thus $\widehat{I}_{S}=\frac{\sum_{k \in V} \widehat{I}_{v}}{n}$ where $n$ is the total number of routes in set $V$.

\subsubsection{Model implementation and parameterisation}

Consider that recipient country $R$ imports commodities from a set of donor countries $G$, and let $g \in G$. The model can evaluate the inspection strategies for countries $G$ which differ with regards to their climatic similarity to country $R$ and in the number of species transported to country $R$. In the model, species are transported to country $R$ through four routes, each representing an extreme combination of climatic similarity and number of transported species. We define the set of routes $V$ to be the following: $v_{1}$ : High number of transported species and $g_{1}$ is climatically similar to $R$.

$v_{2}$ : Low number of transported species and $g_{2}$ is climatically similar to $R$.

$v_{3}$ : High number of transported species and $g_{3}$ is not climatically similar to $R$.

$v_{4}$ : Low number of transported species and $g_{4}$ is not climatically similar to $R$.

It must be noted that this scenario represents a snapshot in time, and that the number of species transported along each route and the climatic similarity of the recipient and donor countries will vary temporally. However if updated regularly, inspection strategies should keep up with these variations (see Section 4.3).

We define the set of inspection strategies $S$ to be the following:

$s_{1}$ : Border control with no prioritisation. Routes are inspected equally.

$s_{2}$ : Border control with prioritisation based on colonisation pressure, measured as the number of species transported along a route $T_{v}$. Routes with a high $T_{v}$ will be an inspection priority. $s_{3}$ : Border control with prioritisation based on the likelihood of establishment, measured as the climatic similarity between $R$ and $g$. Routes from countries $G$ that are climatically similar to $R$ will be an inspection priority.

$s_{4}$ : Border control with prioritisation based on establishment debt, measured as the number of species transported along a

\section{Table 2}

Parameter values for the theoretical model used to evaluate four inspection strategies that aim to prevent the introduction of species that are transported along four routes to recipient country $R$. For all inspection strategies the probability that introduced species will fail to establish is constant at 0.98 , and is based on an estimate from di Castri (1989).

\begin{tabular}{llllll}
\hline Parameter & \multicolumn{3}{l}{ Route } & & \\
\cline { 2 - 6 } & $v_{1}$ & $v_{2}$ & \multicolumn{1}{l}{$v_{3}$} & \multicolumn{1}{l}{$v_{4}$} \\
\hline Number of species transported $\left(T_{v}\right)$ & $100^{\mathrm{a}}$ & $20^{\mathrm{a}}$ & $100^{\mathrm{a}}$ & $20^{\mathrm{a}}$ \\
Probability of surviving transport $\left(\overline{\bar{P}}_{v}\right)$ & $0.19^{\mathrm{b}}$ & $0.19^{\mathrm{b}}$ & $0.19^{\mathrm{b}}$ & $0.19^{\mathrm{b}}$ \\
Probability of establishment failure $\left(\bar{P}_{v}\right)$ & $0.97^{\mathrm{c}}$ & $0.97^{\mathrm{c}}$ & $0.99^{\mathrm{c}}$ & $0.99^{\mathrm{c}}$ \\
\hline a & & & & \\
b Own assumption. & & & & \\
c Based on Stanaway et al. (2001). & & & &
\end{tabular}


route that will establish (i.e. $E_{v}$ ). Routes from countries $G$ that are climatically similar to $R$ and that have a high $T_{v}$ will be an inspection priority.

The model was parameterised using estimates from publications and assumptions (see Tables 2-4 for parameters). As data to parameterise the model were available at a species level, species was used as the unit of measurement. The likelihood that an organism survives transportation is influenced by numerous interacting factors (e.g. the type of organism and vector, see Briski et al., 2014). As this work was not vector- or species-specific, for simplicity it was assumed that the probability of surviving transport $\overline{\bar{P}}_{v}$ is constant for all routes (Table 2). Estimates of the probability of establishment failure $\bar{P}_{v}$ were based on the assumption that of the total number of species introduced, the proportion that are establishment failures will be constant. However, the contribution that species transported along the different routes make to this proportion will vary based on the climatic similarity between the recipient and donor countries (Table 2 ). In other words, the proportion of species that are establishment failures will be higher for routes that connect climatically dissimilar countries, than for routes that connect climatically similar countries (Table 2). Similarly estimates of the probability of detection $P_{v}$ were based on the assumption that total inspection effort is limited and constant, and thus of the total number of species introduced the proportion that are detected is constant. However based on the inspection strategy, the proportion of inspection effort allocated to each route will vary and as a consequence the contribution species transported along different routes make to this proportion will also vary (Tables 3 and 4 ). In other words, the probability of detection will be higher for routes that are an inspection priority (i.e. higher proportion of inspection effort) than for routes that are not (Table 4). These assumptions may not hold in all instances and a variety of potentially important factors were not considered, however, this simple model served the purpose of the work.

\section{Results}

South Africa's establishment debt varies seasonally, with donor countries varying in their contribution (Fig. 2). There is large seasonal variation in the contribution of northern hemisphere countries to the establishment debt, but the contribution of southern hemisphere countries is relatively constant (Fig. 2). As there is little seasonal variation in the colonisation pressure posed to South Africa from foreign countries (but see Russia; Fig. S6), these temporal changes in establishment debt are largely driven by seasonal variation in the likelihood of establishment (Fig. S7). Consequently, the number of species that are likely to be introduced from many foreign countries to South Africa is high and constant across the seasons but there is seasonal variation in the likelihood that these species will establish. For example, during all seasons a number of European countries pose a high colonisation pressure to South

Table 3

Parameter values for the proportion of inspection effort $I_{v}$ allocated under four inspection strategies that aim to prevent the introduction of species transported along four routes to recipient country $R$. Total inspection effort for all inspection strategies is constant.

\begin{tabular}{lllll}
\hline Inspection strategy & \multicolumn{2}{l}{ Route } & & \\
\cline { 2 - 5 } & $v_{1}$ & $v_{2}$ & $v_{3}$ & $v_{4}$ \\
\hline No priorities $\left(s_{1}\right)$ & 0.25 & 0.25 & 0.25 & 0.25 \\
Colonisation pressure $\left(s_{2}\right)$ & 0.42 & 0.08 & 0.42 & 0.08 \\
Likelihood of establishment $\left(s_{3}\right)$ & 0.42 & 0.42 & 0.08 & 0.08 \\
Establishment debt $\left(s_{4}\right)$ & 0.55 & 0.22 & 0.22 & 0.01 \\
\hline
\end{tabular}

Table 4

Parameter values for the probability that species transported along four routes to recipient country $R$ will be detected $P_{v}$ under four inspection strategies. The probability of detection for all inspection strategies is constant at 0.24 , and is based on an estimate from Work et al. (2005) for non-refrigerated maritime cargo.

\begin{tabular}{lllll}
\hline Inspection strategy & \multicolumn{3}{l}{ Route } & \\
\cline { 2 - 5 } & $v_{1}$ & $v_{2}$ & $v_{3}$ & $v_{4}$ \\
\hline No priorities $\left(s_{1}\right)$ & 0.24 & 0.24 & 0.24 & 0.24 \\
Colonisation pressure $\left(s_{2}\right)$ & 0.40 & 0.08 & 0.40 & 0.08 \\
Likelihood of establishment $\left(s_{3}\right)$ & 0.40 & 0.40 & 0.08 & 0.08 \\
Establishment debt $\left(s_{4}\right)$ & 0.53 & 0.21 & 0.21 & 0.01 \\
\hline
\end{tabular}

Africa (Fig. S6), however, the contribution of these countries to establishment debt in the southern hemisphere summer is low or medium (Fig. 2). Thus, South Africa's establishment debt is greatest in the southern hemisphere autumn and spring (highest number of countries that contribute a medium or high number of species to establishment debt; Fig. 3) when there is an increase in the climatic similarity between South Africa and northern hemisphere countries with which there are consistent, strong trade and tourism links (e.g. European and Asian countries; Fig. 2; Figs S6 and S7). The number of countries that contribute a high number of species to the establishment debt changes very little across the seasons (25 countries in summer to 34 countries in spring; Fig. 3), but the identity of these countries varies seasonally (Fig. 2). For all seasons there was a higher percentage of countries for which colonisation pressure was low and the likelihood of establishment was high than vice versa (Table 5). Thus, South Africa's establishment debt is often limited by a lack of transport opportunities.

A similar total number of species was detected in the inspection strategy with no priorities than when the inspection strategy prioritised on the likelihood of establishment (where vectors from countries with a high climatic similarity are prioritised) was employed, however, more establishers were detected in the latter than the former (Fig. 4). A higher total number of species was detected when priorities were based on either colonisation pressure (where vectors from countries from which a high number of species are transported are prioritised) or establishment debt (where vectors from countries with a high climatic similarity and from which a high number of species are transported are prioritised) than when there were no priorities or when priorities were based on the likelihood of establishment (Fig. 4). Although the total number of detected species was higher when priorities were based on colonisation pressure than when based on establishment debt, a higher number of establishers were detected in the latter strategy than in the former (Fig. 4). In comparison to the inspection strategy with no priorities, in the prioritised inspection strategies less inspection effort was allocated per establisher and strategy efficacy was higher (Fig. 5). Less inspection effort was allocated per establisher and efficacy was higher when the inspection strategy prioritised based on colonisation pressure was implemented than when that prioritised based on the likelihood of establishment was employed (Fig. 5). The inspection strategy prioritised based on establishment debt had the lowest amount of inspection effort allocated per establisher and the highest efficacy, with between 6 and $16 \%$ more establishers detected when this strategy was employed than when the other inspection strategies were implemented (Fig. 5).

\section{Discussion}

Evaluations of the risk of invasion can be used to inform management strategies by aiding decision making and prioritisation. Studies that have attempted to achieve this include work on the risk 
Southern hemisphere summer

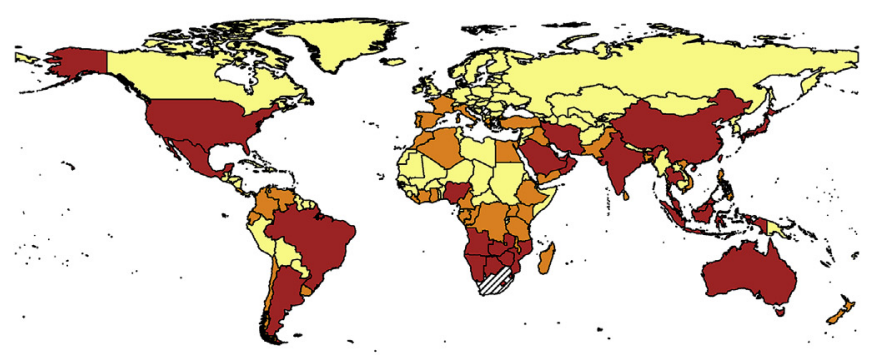

Southern hemisphere winter

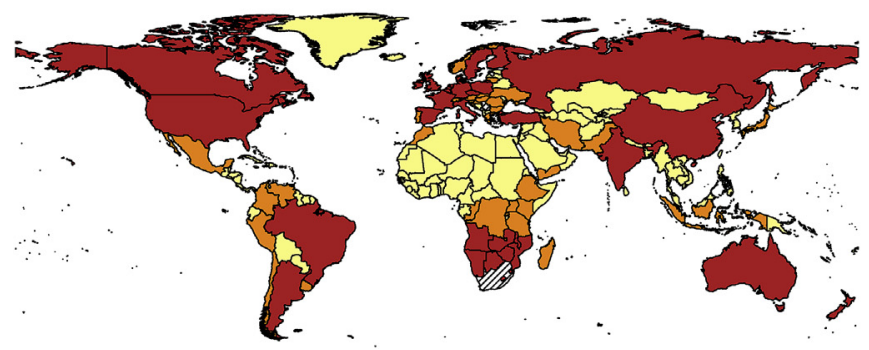

Southern hemisphere autumn

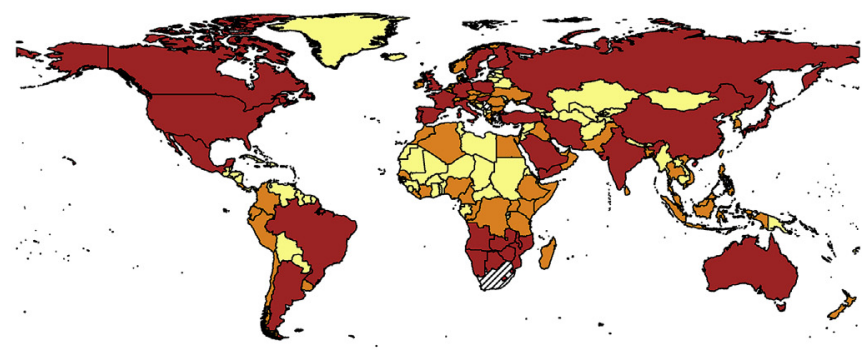

Southern hemisphere spring

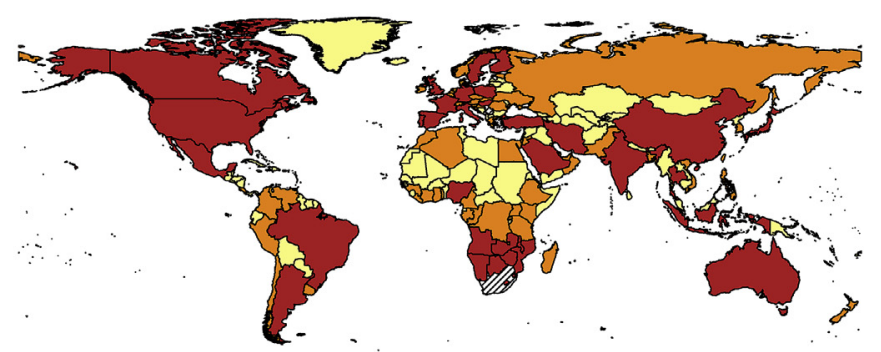

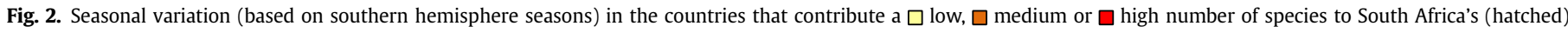
establishment debt.

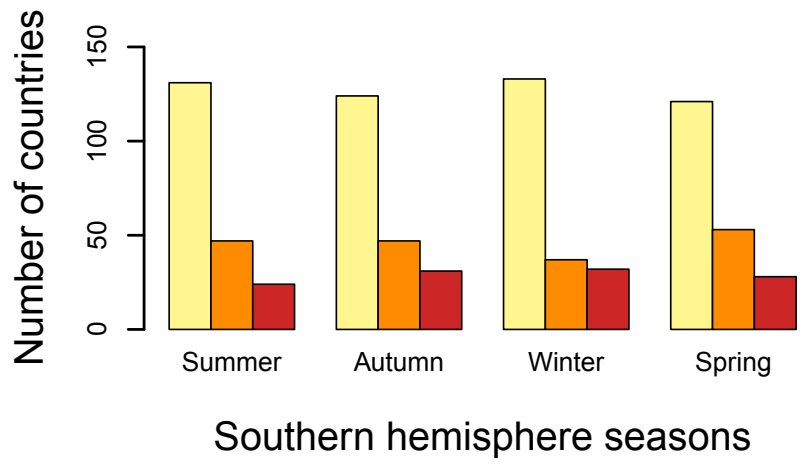

Fig. 3. Seasonal variation (based on southern hemisphere seasons) in the number of countries that contribute a $\square$ low, $\square$ medium or $\square$ high number of species to South Africa's establishment debt. prioritised inspection strategies.

\subsection{Geographical and seasonal variations in establishment debt}

Geographical and seasonal variations in the likelihood that climatically sensitive organisms will be introduced and establish has been demonstrated at a global scale (Tatem, 2009; Tatem and Hay, 2007; Tatem et al., 2006a). However, unlike the research presented here, these studies have tended to focus on specific transport vectors (e.g. the Worldwide Airline Network, see Tatem, 2009; Tatem and Hay, 2007) or species (e.g. Aedes albopictus, see Tatem et al., 2006a). The results presented here are comparable to the findings of a study by Tatem and Hay (2007) on the risk of invasion posed by climatically sensitive organisms transported by the Worldwide Airline Network. Although the period of the year in which South Africa has the greatest establishment debt (southern

Table 5

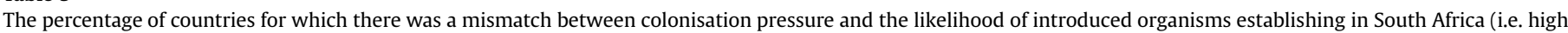
colonisation pressure and low likelihood of establishment or vice versa).

\begin{tabular}{|c|c|c|}
\hline Southern hemisphere season & Low colonisation pressure and high likelihood of establishment & High colonisation pressure and low likelihood of establishment \\
\hline Summer & 16.8 & 7.9 \\
\hline Autumn & 8.4 & 0.5 \\
\hline Winter & 6.9 & 5.0 \\
\hline Spring & 15.3 & 1.0 \\
\hline
\end{tabular}

of invasion posed globally by shipping. For example, it has been demonstrated that decreasing the risks posed by a few high risk ports would greatly reduce marine invasions globally (Seebens et al., 2013). Here the number of climatically sensitive species that might establish in South Africa's natural or semi-natural environments was evaluated, and how this establishment debt varies seasonally and across donor regions was demonstrated. Additionally, a theoretical model was used to demonstrate the importance of considering underlying establishment debt when developing hemisphere spring and autumn) is not in line with Tatem and Hay's (2007) global results (globally the risk of invasion is highest in southern hemisphere winter), the results presented here were supported by their findings for South African airports. Similar to our results, the risk of invasion posed to South African airports is greater in July (winter in this study) than in January (summer in this study), when there is an increase in airline traffic from airports which are, for that month, climatically similar to South African airports. Additionally, South African and northern hemisphere 


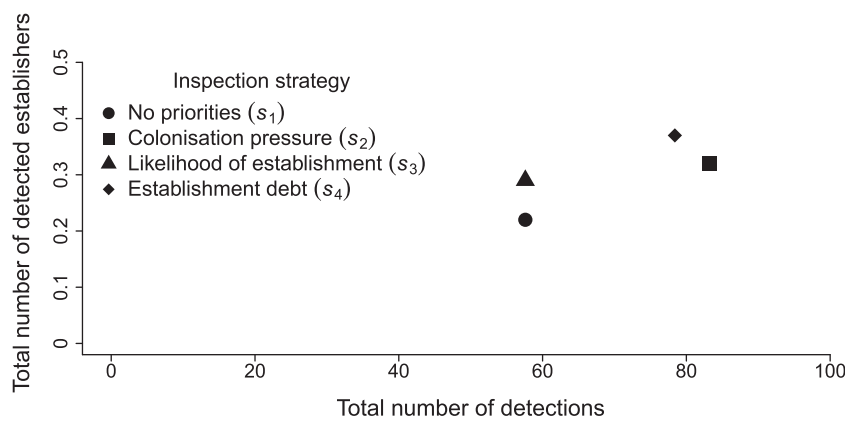

Fig. 4. The total number of detections and total number of detected establishers for border control following four different inspection strategies. The total number of detections $D_{s}$ is the number of species detected $D_{v}$ by border control across all routes. Similarly, the total number of detected establishers $\widehat{D}_{s}$ is the number of establishers that are detected by border control $\widehat{D}_{v}$ across all routes.

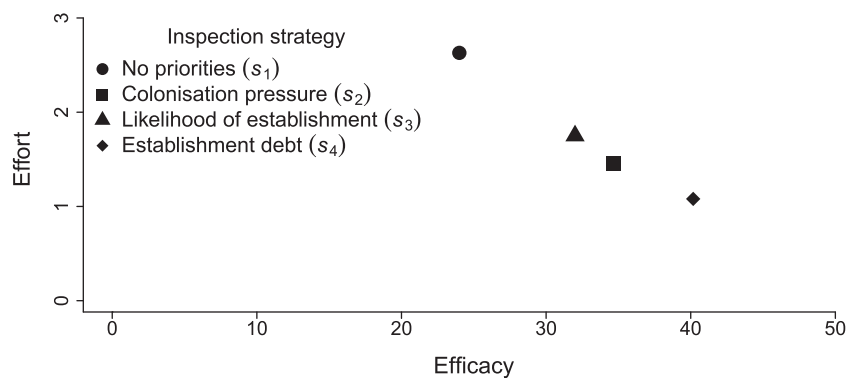

Fig. 5. The efficacy and effort of four inspection strategies for border control. Strategy efficacy $E_{s}$ is the percentage of establishers $E_{v}$ detected by border control $\widehat{D}_{v}$ across all routes. Effort $\widehat{I}_{s}$ is the average amount of inspection effort allocated by border control across all routes to detect each establisher.

airports are more climatically similar in April (southern hemisphere autumn and northern hemisphere spring) than in January (southern hemisphere summer and northern hemisphere winter) when climates in both hemispheres are more extreme.

These geographical and seasonal variations can have consequences for national management strategies that aim to prevent invasions. For example, resources spent on targeting vectors from countries during times of the year when the introduced organisms are unlikely to establish, due to an unsuitable climate, could be reallocated to target vectors from countries at times of the year when establishment debt is high. Although targeted inspections based on perceived risks are employed by existing border agencies (McCullough et al., 2006; Saccaggi et al., 2016) and the type of strategy discussed above would not unfairly discriminate against countries, it is important to note that in practice such decisions would need to consider political sensitivities and international treaties. The similarities between the results presented here and those of Tatem and Hay (2007) highlight that studies at global scales can be used to inform national level management strategies. However, the large scale of global studies might mean that the risks posed to developing countries are underestimated (for example, what might be a relatively high risk route for a developing country might be low risk globally) and consequently studies at national scales are also required.

\subsection{Incorporating establishment debt into prioritised inspection strategies}

Efforts that link underlying risks to prevention strategies (e.g. Drake and Lodge, 2004; Seebens et al., 2013) have demonstrated that strategic management can reduce invasions. Our simple theoretical model demonstrated that prioritising inspection strategies, particularly based on establishment debt (i.e. the number of species that will establish), further diminishes the risk of invasion. For example, when prioritising inspection strategies based on the number of species that will be introduced to the recipient region (i.e. colonisation pressure), resources will be allocated towards vectors that transport species with little chance of establishing. In contrast, prioritisation based on the number of species that will establish (i.e. establishment debt) better allocates the available resources towards vectors that are likely to transport many species that have the potential to establish and become invasive. However as discussed above, establishment debt varies geographically and seasonally (Seebens et al., 2013; Tatem and Hay, 2007), and thus prioritised inspection strategies based on this factor cannot be static and will have to be revised regularly (e.g. seasonally). These strategies need to be informed by detailed national or regional level studies that consider both the number of organisms likely to be introduced from the donor region (see Bacon et al., 2012; Work et al., 2005) and the climatic similarity of the donor and recipient regions. However, the results of such studies must be carefully interpreted. For example, as the results of this work demonstrated that South Africa's establishment debt is greatest in southern hemisphere spring and autumn, one might conclude that resources for border control should be increased during these seasons (theoretically possible but in a real world situation such action would be expensive and impractical). However, as the number of countries that contribute a high number of species to South Africa's establishment debt is relatively constant across the seasons, it would be best if total inspection effort remains constant and that the targeted countries are revised seasonally.

\subsection{Long-term changes in establishment debt}

The work presented here only considers seasonal changes to colonisation pressure and the likelihood of establishment, however, longer-term changes in these factors will influence establishment debt (Floerl et al., 2013; Ware et al., 2014). For example, changes to trade will expose the recipient country to new pools of exotic species and will cause long-term increases in the number of introduced species (Bradley et al., 2012; McCullough et al., 2006). For all seasons, the contribution of many climatically similar countries to South Africa's establishment debt is limited due to weak transport links (e.g. Peru), and consequently changes to trade or transportation networks may have a particularly large impact on establishment debt in the future. Climate change will drive longterm changes in the likelihood of establishment (Hellmann et al., 2008), and countries that are currently climatically similar to South Africa may be less so in the future (e.g. New Zealand; Kriticos, 2012). If inspection strategies are updated periodically they should, however, keep up with these changes, and if the availability of inspection data improves, real-time predictions may be possible in the future.

\subsection{Limitations of the assessment of establishment debt}

This assessment was not species-specific and focused on stowaway introductions that pose a risk to natural or semi-natural environments. The vectors of stowaway organisms are often difficult to identify and although this work would have benefitted from more detailed vector data (e.g. data on container offloads and tourism data that included both foreign visitors and South African residents) these data could not be obtained. As a consequence, coarse vector data (tourism and trade data) that were not speciesspecific were used (for species-specific assessments see Benedict 
et al., 2007; Tatem et al., 2006a). Although trade may be the primary or sole vector for many stowaway organisms (e.g. marine organisms that stowaway on ships), there are organisms for which tourists, or their means of transportation, act as vectors (e.g. mosquitos are often transported on aeroplanes, see Gratz et al., 2000). As such we included both tourism and trade data in our analysis, and as we have no evidence that either contributes more to stowaway introductions in South Africa (due to a lack of inspection data, see below) these factors were weighted equally.

Although the use of coarse vector data and climate matching techniques might have resulted in an overestimation of colonisation pressure and the likelihood of establishment, coarse vector data have been used to successfully predict introductions (Tatem and Hay, 2007; Thuiller et al., 2005), and similar climate matching techniques have successfully identified regions where invasive species occur (Richardson and Thuiller, 2007). Additionally, throughout the methodology a precautionary approach was followed, which would favour over-estimates rather than underestimates of establishment debt. Although the methodology could be implemented using finer scale vector data (e.g. shipping data) and climate matching techniques (e.g. the climatic distance between ports), it is likely that the variations demonstrated here would still be evident. Finally, although it would have been beneficial to validate the results using inspection data, detailed inspection records are not currently available from inspectors at South Africa's ports of entry.

Establishment debt is influenced by various factors that were not included in the estimates presented here, for example, the likelihood that an organism would survive transportation (Areal et al., 2008; Seebens et al., 2013). Additionally, various speciesspecific factors will influence establishment debt and how this debt varies over time (e.g. phenology, see Godoy et al., 2009; Liebhold et al., 2006). Extending this work in the future and including these elements would be beneficial. Finally, this work focused on stowaway organisms that are sensitive to small changes in climate. There are many real-world cases that demonstrate the importance of seasonality to organism introduction and establishment (e.g. the phenomenon of airport malaria, see Gratz et al., 2000; Tatem et al., 2006b), but there are notable exceptions. For example, some organisms introduced in a dormant state might be able survive in that state until the environment changes and becomes suitable.

Finally, subjective (and relative) thresholds were used to determine whether colonisation pressure and the likelihood of establishment are low, medium or high. These thresholds served their purpose in this analysis, however, due to disparities in available resources, these thresholds should vary regionally, and ought to be determined based on the trade-off between intensively surveying imports from a few high risk countries, or rapidly surveying imports from a higher number of countries (e.g. high and medium risk countries). Additionally, to better inform the selection of these thresholds, further research on what constitutes a low or high level of, for example, climatic similarity with regards to the likelihood of invasion is required.

\subsection{Opportunities for future work}

Although this work focused on stowaway introductions, the methodology presented here could easily be adapted to make use of commodity-specific data, and thus could be used to evaluate the number of contaminant introductions that might establish. Although such work has the potential to be extremely useful, there are a few factors that would have to be considered in such an analysis, for example, the availability of hosts in the recipient region (see Bacon et al., 2014) and the artificial environments created by humans for agriculture. It is, however, likely that the geographical and seasonal variations demonstrated here would also be evident in such an analysis.

\section{Conclusions}

This analysis demonstrated that the number of climatically sensitive stowaway species that may be introduced and establish in natural or semi-natural environments varies across donor regions and seasons. As a consequence resource allocation and border control inspections could be improved if vectors from countries are targeted during periods of the year when a high number of species with the potential to establish are introduced. This implies that inspection prioritisation for border control should be done at a country or local level and thus that national studies of establishment debt are required.

\section{Role of the funding source}

The funder had no role in study design; the collection, analysis and interpretation of data; writing the manuscript and the decision to submit the manuscript for publication.

\section{Acknowledgements}

This work was supported by the South African National Department of Environment Affairs through its funding of the South African National Biodiversity Institute's Invasive Species Programme. Additional funding was provided by the DST-NRF Centre for Invasion Biology. MR acknowledges funding from the South African Research Chairs Initiative of the Department of Science and Technology and National Research Foundation of South Africa. We thank Marnus Stoltz for his help with the mathematical notation and Philip Hulme, Jan Pergl and Charles Griffiths for constructive comments on an earlier draft of this manuscript.

\section{Appendix A. Supplementary data}

Supplementary data related to this article can be found at http:// dx.doi.org/10.1016/j.jenvman.2016.05.023.

\section{References}

Andow, D.A., 2003. Pathways-based risk assessment of exotic species invasions. In: Ruiz, G.M., Carlton, J.T. (Eds.), Invasive Species: Vectors and Management Strategies. Island Press, Washington, pp. 439-458.

Areal, F.J., Touza, J., MacLeod, A., Dehnen-Schmutz, K., Perrings, C., Palmieri, M.G., Spence, N.J., 2008. Integrating drivers influencing the detection of plant pests carried in the international cut flower trade. J. Environ. Manag. 89, 300-307.

Bacon, S.J., Bacher, S., Aebi, A., 2012. Gaps in border controls are related to quarantine alien insect invasions in Europe. PLoS One 7, e47689.

Bacon, S.J., Aebi, A., Calanca, P., Bacher, S., 2014. Quarantine arthropod invasions in Europe: the role of climate, hosts and propagule pressure. Divers. Distrib. 20 84-94.

Barry, S.C., Hayes, K.R., Hewitt, C.L., Behrens, H.L., Dragsund, E., Bakke, S.M., 2008 Ballast water risk assessment: principles, processes, and methods. ICES J. Mar. Sci. $65,121-131$.

Benedict, M.Q., Levine, R.S., Hawley, W.A., Lounibos, L.P., 2007. Spread of the tiger: global risk of invasion by the mosquito Aedes albopictus. Vector Borne Zoonotic Dis. 7, 76-85.

Bivand, R., Lewin-Koh, N., 2013. maptools: Tools for Reading and Handling Spatial Objects [WWW Document]. URL. http://cran.r-project.org/package=maptools (accessed 11.11.13.).

Blackburn, T.M., Pyšek, P., Bacher, S., Carlton, J.T., Duncan, R.P., Jarošík, V. Wilson, J.R.U., Richardson, D.M., 2011. A proposed unified framework for biological invasions. Trends Ecol. Evol. 26, 333-339.

Bradie, J., Pietrobon, A., Leung, B., 2015. Beyond species-specific assessments: an analysis and validation of environmental distance metrics for non-indigenous species risk assessment. Biol. Invasions 17, 3455-3465.

Bradley, B.A., Blumenthal, D.M., Early, R., Grosholz, E.D., Lawler, J.J., Miller, L.P. Sorte, C.J.B., D’Antonio, C.M., Diez, J.M., Dukes, J.S., Ibanez, I., Olden, J.D., 2012 
Global change, global trade, and the next wave of plant invasions. Front. Ecol. Environ. 10, 20-28.

Briski, E., Chan, F.T., MacIsaac, H.J., Bailey, S.A., 2014. A conceptual model of community dynamics during the transport stage of the invasion process: a case study of ships' ballast. Divers. Distrib. 20, 236-244.

Busby, J.R., 1991. BIOCLIM - a bioclimate analysis and prediction system. In: Margules, C.R., Austin, M.P. (Eds.), Nature Conservation: Cost Effective Biological Surveys and Data Analysis. CSIRO, Melbourne, pp. 64-68.

Derraik, J.G.B., 2004. Exotic mosquitoes in New Zealand: a review of species intercepted, their pathways and ports of entry. Aust. N. Z. J. Public Health 28, 433-444.

di Castri, F., 1989. History of biological invasions with special emphasis on the old world. In: Drake, J.A. (Ed.), Biological Invasions: a Global Perspective. John Wiley \& Sons Ltd, Chichester, pp. 1-30.

Drake, J.M., Lodge, D.M., 2004. Global hot spots of biological invasions: evaluating options for ballast - water management. Proc. R. Soc Lond. B 271, 575-580.

Faulkner, K.T., Robertson, M.P., Rouget, M., Wilson, J.R.U., 2014. A simple, rapid methodology for developing invasive species watch lists. Biol. Conserv. 179, 25-32.

Floerl, O., Rickard, G., Inglis, G., Roulston, H., 2013. Predicted effects of climate change on potential sources of non-indigenous marine species. Divers. Distrib. 19, 257-267.

Giliomee, J.H., 2011. Recent establishment of many alien insects in South Africa - a cause for concern. Afr. Entomol. 19, 151-155.

Godoy, O., Richardson, D.M., Valladares, F., Castro-Díez, P., 2009. Flowering phenology of invasive alien plant species compared with native species in three Mediterranean-type ecosystems. Ann. Bot. 103, 485-494.

Gratz, N.G., Steffen, R., Cocksedge, W., 2000. Why aircraft disinsection? Bull. World Health Organ. 78, 995-1004.

Hellmann, J.J., Byers, J.E., Bierwagen, B.G., Dukes, J.S., 2008. Five potential consequences of climate change for invasive species. Conserv. Biol. 22, 534-543.

Hulme, P.E., Bacher, S., Kenis, M., Klotz, S., Kühn, I., Minchin, D., Nentwig, W. Olenin, S., Panov, V., Pergl, J., Pyšek, P., Roques, A., Sol, D., Solarz, W., Vilà, M. 2008. Grasping at the routes of biological invasions: a framework for integrating pathways into policy. J. Appl. Ecol. 45, 403-414.

Keller, R.P., Drake, J.M., Drew, M.B., Lodge, D.M., 2011. Linking environmental conditions and ship movements to estimate invasive species transport across the global shipping network. Divers. Distrib. 17, 93-102.

Kriticos, D.J., 2012. Regional climate-matching to estimate current and future sources of biosecurity threats. Biol. Invasions 14, 1533-1544.

Levine, J.M., D’Antonio, C.M., 2003. Forecasting biological invasions with increasing international trade. Conserv. Biol. 17, 322-326.

Liebhold, A.M., Work, T.T., McCullough, D.G., Cavey, J.F., 2006. Airline baggage as a pathway for alien insect species invading the. U. S. Am. Entomol. 52, 48-54.

Lockwood, J.L., Cassey, P., Blackburn, T.M., 2009. The more you introduce the more you get: the role of colonization pressure and propagule pressure in invasion ecology. Divers. Distrib. 15, 904-910.

MacIsaac, H.J., Robbins, T.C., Lewis, M.A., 2002. Modeling ships' ballast water as invasion threats to the Great Lakes. Can. J. Fish. Aquat. Sci. 59, 1245-1256.

McCullough, D.G., Work, T.T., Cavey, J.F., Liebhold, A.M., Marshall, D., 2006. Interceptions of nonindigenous plant pests at US ports of entry and border crossings over a 17-year period. Biol. Invasions 8, 611-630.

Mumford, J.D., 2002. Economic issues related to quarantine in international trade. Eur. Rev. Agric. Econ. 29, 329-348.

New, M., Lister, D., Hulme, M., Makin, I., 2002. A high-resolution data set of surface climate over global land areas. Clim. Res. 21, 1-25.
Olson, D.M., Dinerstein, E., Wikramanayake, E.D., Burgess, N.D., Powell, G.V.N., Underwood, E.C., D'Amico, J.A., Itoua, I., Strand, H.E., Morrison, J.C. Loucks, C.J., Allnutt, T.F., Ricketts, T.H., Kura, Y., Lamoreux, J.F., Wettengel, W.W., Hedao, P., Kassem, K.R., 2001. Terrestrial ecoregions of the world: a new map of life on earth. Bioscience 51, 933-938.

Pimentel, D., McNair, S., Janecka, J., Wightman, J., Simmonds, C., O'Connell, C. Wong, E., Russel, L., Zern, J., Aquino, T., Tsomondo, T., 2001. Economic and environmental threats of alien plant, animal, and microbe invasions. Agric. Ecosyst. Environ. 84, 1-20.

R Core Team, 2013. R: a Language and Environment for Statistical Computing [WWW Document]. URL. http://www.r-project.org/ (accessed 11.11.13.).

Richardson, D.M., Thuiller, W., 2007. Home away from home - objective mapping of high-risk source areas for plant introductions. Divers. Distrib. 13, 299-312.

Rouget, M., Robertson, M.P., Wilson, J.R.U., Hui, C., Essl, F., Renteria, J.L., Richardson, D.M., 2016. Invasion debt - quantifying future biological invasions. Divers. Distrib. 22, 445-456.

Saccaggi, D.L., Karsten, M., Robertson, M.P., Kumschick, S., Somers, M.J., Wilson, J.R.U., Terblanche, J.S., 2016. Methods and approaches for the management of arthropod border incursions. Biol. Invasions 18, 1057-1075.

Seebens, H., Gastner, M.T., Blasius, B., 2013. The risk of marine bioinvasion caused by global shipping. Ecol. Lett. 16, 782-790.

Simberloff, D., 2006. Risk assessments, blacklists, and white lists for introduced species: are predictions good enough to be useful? Agric. Resour. Econ. Rev. 35, $1-10$.

Simberloff, D., Martin, J.-L., Genovesi, P., Maris, V., Wardle, D.A., Aronson, J., Courchamp, F., Galil, B., García-Berthou, E., Pascal, M., Pyšek, P., Sousa, R., Tabacchi, E., Vilà, M., 2013. Impacts of biological invasions: what's what and the way forward. Trends Ecol. Evol. 28, 58-66.

Stanaway, M.A., Zalucki, M.P., Gillespie, P.S., Rodriguez, C.M., Maynard, G.V., 2001. Pest risk assessment of insects in sea cargo containers. Aust. J. Entomol. 40, 180-192.

Surkov, I.V., Oude Lansink, A.G.J.M., van Kooten, O., van der Werf, W., 2008. A model of optimal import phytosanitary inspection under capacity constraint. Agric. Econ. 38, 363-373.

Tatem, A.J., Hay, S.I., Rogers, D.J., 2006a. Global traffic and disease vector dispersal. Proc. Natl. Acad. Sci. U. S. A. 103, 6242-6247.

Tatem, A.J., Rogers, D.J., Hay, S.I., 2006b. Global transport networks and infectious disease spread. Adv. Parasitol. 62, 294-343.

Tatem, A.J., Hay, S.I., 2007. Climatic similarity and biological exchange in the worldwide airline transportation network. Proc. R. Soc. Lond. B 274, 1489-1496.

Tatem, A.J., 2009. The worldwide airline network and the dispersal of exotic species: 2007-2010. Ecography 32, 94-102.

Thuiller, W., Richardson, D.M., Pyšek, P., Midgley, G.F., Hughes, G.O., Rouget, M., 2005. Niche-based modelling as a tool for predicting the risk of alien plant invasions at a global scale. Glob. Chang. Biol. 11, 2234-2250.

Ware, C., Berge, J., Sundet, J.H., Kirkpatrick, J.B., Coutts, A.D.M., Jelmert, A., Olsen, S.M., Floerl, O., Wisz, M.S., Alsos, I.G., 2014. Climate change, nonindigenous species and shipping: assessing the risk of species introduction to a high-Arctic archipelago. Divers. Distrib. 20, 10-19.

Westphal, M.I., Browne, M., MacKinnon, K., Noble, I., 2008. The link between international trade and the global distribution of invasive alien species. Biol. Invasions 10, 391-398.

Work, T.T., McCullough, D.G., Cavey, J.F., Komsa, R., 2005. Arrival rate of nonindigenous insect species into the United States through foreign trade. Biol. Invasions 7, 323-332. 


\section{Supplementary Materials}

\section{Materials and methods}

The number of species that are likely to establish in South Africa (referred to as 'establishment debt' (Rouget et al., 2016)) was assessed by taking into account two key stages of the invasion continuum (i.e. introduction and establishment (Blackburn et al., 2011)). For each season the number of stowaway species that would be introduced from a foreign country to South Africa was assessed, and the likelihood that these species would establish was evaluated. These results were combined to determine how establishment debt varies seasonally and how donor regions vary in their contribution to this debt. In this paper, colonisation pressure refers to the number of species introduced (Lockwood et al., 2009), and the likelihood of establishment is the likelihood that a species will be introduced to an area with a suitable climate and establish. Note, the eventual impact of the species is not considered here.

\subsection{Colonisation pressure}

Trade and tourism data were used as a proxy for colonisation pressure. Monthly countrylevel data on the number of foreign tourists and the value of commodity imports (in South African Rand) were obtained from Statistics South Africa and the South African Department of Trade and Industry for 2007 to 2011 . These data were used to determine the monthly colonisation pressure posed by each foreign country to South Africa. Let $j \in M$, where $M$ is the months of the year, and let $H_{j}$ be average tourism and $W_{j}$ be average imports for month $j$. For each month, rescaled tourism and import values were the average tourism $H_{j}$ or import $W_{j}$ value divided by total tourism $\sum_{i \in M} H_{i}$ or imports $\sum_{i \in M} W_{i}$. For each month the colonisation pressure posed by each foreign country was estimated as the sum of the rescaled tourism and trade values divided by two (i.e. tourism and trade were weighted equally):

$$
M_{j}=\frac{1}{2}\left(\frac{H_{j}}{\sum_{i \in M} H_{i}}+\frac{W_{j}}{\sum_{i \in M} W_{i}}\right)
$$

Seasonal results were obtained by averaging across months that fall into southern hemisphere seasons (i.e. winter is June-August; spring is September-November etc.). The relative seasonal colonisation pressure posed by each country was designated as low, medium or high (colonisation pressures greater than or equal to the $75^{\text {th }}$ percentile were high; greater than or equal to the $50^{\text {th }}$ percentile were medium; and the remainder were low). 


\subsection{Likelihood of establishment}

The likelihood that organisms introduced from foreign countries could establish in South Africa (given that they had survived transportation and were introduced) was assessed using two climate matching techniques. The climatic similarity between South Africa and foreign countries was firstly evaluated at a city level using a point-based climate matching technique, and secondly at a country level using a grid-based method. The two climate matching techniques measured the likelihood of different extents of establishment. The point-based technique measured the likelihood that an introduced organism will survive and reproduce at the point of introduction, while the grid-based method measured the likelihood that an introduced organism will survive and reproduce a significant distance from the point of introduction. The results of the two methods were then combined to obtain a measure of the likelihood of establishment.

\subsubsection{Point-based climate matching technique}

Gridded monthly mean temperature and precipitation data from the CRU CL 2.0 dataset at a spatial resolution of 10 minutes (New et al., 2002) were used. For each city, climate data from the relevant cell, as well as from all eight adjacent cells were extracted in ArcMap 10 (ESRI, Red-lands California) (for a similar method see Tatem et al., 2006a). Thus, a maximum of nine climate values were utilised for each city (i.e. nine values for landlocked cities and fewer than nine values for coastal cities). In their evaluation of environmental distance metrics for alien species risk assessments, Bradie et al. (2015) recommended the use of unweighted Euclidean distance, thus this metric was used to determine the climatic distance between cities. To ensure that the temperature and precipitation data lie within the same range and that these parameters are equally weighted when calculating Euclidean distance, standard methods were followed (Barry et al., 2008) and the extracted, monthly temperature and precipitation data were transformed in $\mathrm{R}$ version 3.0.1 ( $\mathrm{R}$ Core Team, 2013) such that the data had a mean of zero and a standard deviation of one (e.g. Keller et al., 2011). For each month, the Euclidean distance in a two dimensional climate space (mean temperature and precipitation) between large South African cities and large foreign cities was determined. Large cities were those that had populations of $\geq 100000$, this cut off was based on the populations of large South African cities (i.e. major hubs that are likely to receive goods and/or to be visited by tourists). It was assumed that trade and tourism was most likely to occur between large cities and consequently that organisms would be introduced from large cities to large cities (e.g. the largest city in New Zealand, Auckland, is the main port of entry for mosquitos; Derraik, 2004). For countries which only have small city populations $(<100000)$, the city with the largest population was included in the analysis. For 
each pairwise comparison the Euclidean distance between all relevant values ( $\leq$ nine values per city, resulting in $\leq 81$ Euclidean distance values per pairwise comparison) was calculated using the 'stats' package in R (R Core Team, 2013). As each pairwise comparison had more than one Euclidean distance value, mean Euclidean distance for each pairwise comparison was calculated (see Figs S1-S4 in supplementary materials for examples of pairwisecomparison results).

Seasonal results for each pairwise comparison were obtained by averaging the Euclidean distance values for months that fall into southern hemisphere seasons (see section 1.1 for information on the classification of the seasons). For each season, the Euclidean distance value from the city in each country that is the most climatically similar to a South African city (i.e. that with the lowest Euclidean distance) was utilised as a measure of climatic similarity between the two countries. This value represents the maximum likelihood that an organism transported from a foreign country to South Africa will find a suitable climate at the point of introduction. Finally, for each season the countries that have a low, medium or high climatic similarity to South Africa were identified. As low Euclidean distance values indicate a high climatic similarity, countries with values less than or equal to the $25^{\text {th }}$ percentile were deemed to have a high climatic similarity to South Africa, those with values less than or equal to the $50^{\text {th }}$ percentile had a medium climatic similarity, and the remainder had a low climatic similarity (see Fig. S5 for a schematic diagram demonstrating the steps followed during point-based climate matching).

\subsubsection{Grid-based climate matching technique}

We used the biome climate matching method presented in Faulkner et al. (2014) and gridded monthly mean precipitation and temperature data (New et al., 2002). Briefly, monthly climate envelopes for each of the biomes present in South Africa (based on the classification of Olson et al., 2001) were modelled and regions of the world with similar climates were identified using the BIOCLIM method (Busby, 1991) in DIVA-GIS (version 7.5.0, http://www.diva-gis.org). For each month the predictions for all biomes were combined in ArcMap by taking the maximum predicted value for each cell. Each cell was assigned a value of 1 if climatically similar to South Africa (all predicted cells: percentiles 0 to 100) or 0 if not climatically similar to South Africa. The monthly climatic similarity of each country to South Africa was determined by calculating the number of grid cells that are climatically similar. Seasonal results were obtained by determining the average number of grid cells that are climatically similar to South Africa (see section 1.1 for information on the classification of the seasons). For each season the countries that have a low, medium or high climatic 
similarity to South Africa were identified using the same thresholds as those used to designate levels of colonisation pressure (see section 1.1).

\subsubsection{Combining point- and grid-based measures of climatic similarity}

For each country the results from the point- and grid-based climate matching methods were combined to obtain a seasonal measure of the likelihood of establishment. Following a precautionary approach, the highest level of climatic similarity was assigned for each season to determine the likelihood that introduced organisms would establish (for example, if a country's climatic similarity was medium for the point-based method and high for the gridbased method then the likelihood of establishment was high). This rule was applied in all instances except when a country had a high climatic similarity for the point-based method and a low climatic similarity for the grid-based method. In such instances, an organism has a high likelihood of becoming established at the point of introduction but will not establish widely (unless environmental conditions change) and thus a medium likelihood of establishment was assigned.

\subsection{Establishment debt}

Establishment debt (i.e. the number of introduced species that will establish over a given time horizon (Rouget et al., 2016)), is calculated as the product of colonisation pressure (i.e. the number of species introduced (Lockwood et al., 2009)), and the likelihood of establishment. Accordingly, for each season, if both colonisation pressure and the likelihood of establishment are high then a given country will contribute a high number of species to South Africa's establishment debt; if either colonisation pressure or the likelihood of establishment are low then the country contributes a low number of species to the establishment debt; and if either component is medium and neither low, then the country will contribute a medium number of species to the debt. The thresholds used to assign levels of establishment debt contribution were standardised by identifying the season (in this case winter) with the greatest number of countries that contribute a high number of species to establishment debt and then using the percentiles for this season to determine establishment debt contribution for all seasons.

Results were mapped using the R package 'maptools' (Bivand and Lewin-Koh, 2013), and the number of countries that contribute a low, medium or high number of species to establishment debt was determined. The percentage of countries for which there was a mismatch between colonisation pressure and likelihood of establishment (i.e. high colonisation pressure but low likelihood of establishment or vice versa) was also calculated. Plotting and analyses were performed in R (R Core Team, 2013). 


\subsection{Theoretical model}

\subsubsection{Model concept}

A simple theoretical model was developed to evaluate four inspection strategies: (1) inspections with no prioritisation, (2) inspections prioritised based on colonisation pressure, (3) inspections prioritised based on the likelihood of establishment, (4) inspections prioritised based on establishment debt (for details see section 1.4.3). The stages of the invasion process were taken into account in the model, and each inspection strategy was evaluated based on four criteria: (1) the total number of species detected (referred to here as total number of detections'), (2) the number of species detected that will establish ('total number of detected establishers'), (3) efficacy ('strategy efficacy') and (4) effort (see sections 1.4.2 and 1.4.3). The model is based on the premise (shown in Fig. 1) that of the species that are transported to a region, a proportion of these species will not survive transportation ('transport casualties'). Of those that do survive transportation ('transport survivors'), a proportion will fail to establish ('establishment failures') due to an unsuitable climate and a proportion, for which the climate is suitable, will establish ('establishers'). Additionally, if border control is implemented a proportion of the transported species will be detected by inspection services (hatched sections of Fig. 1). Of the total number of species detected, some will be transport casualties ('detected casualties'), some will be establishment failures ('detected failures') and some will be establishers ('detected establishers'). 


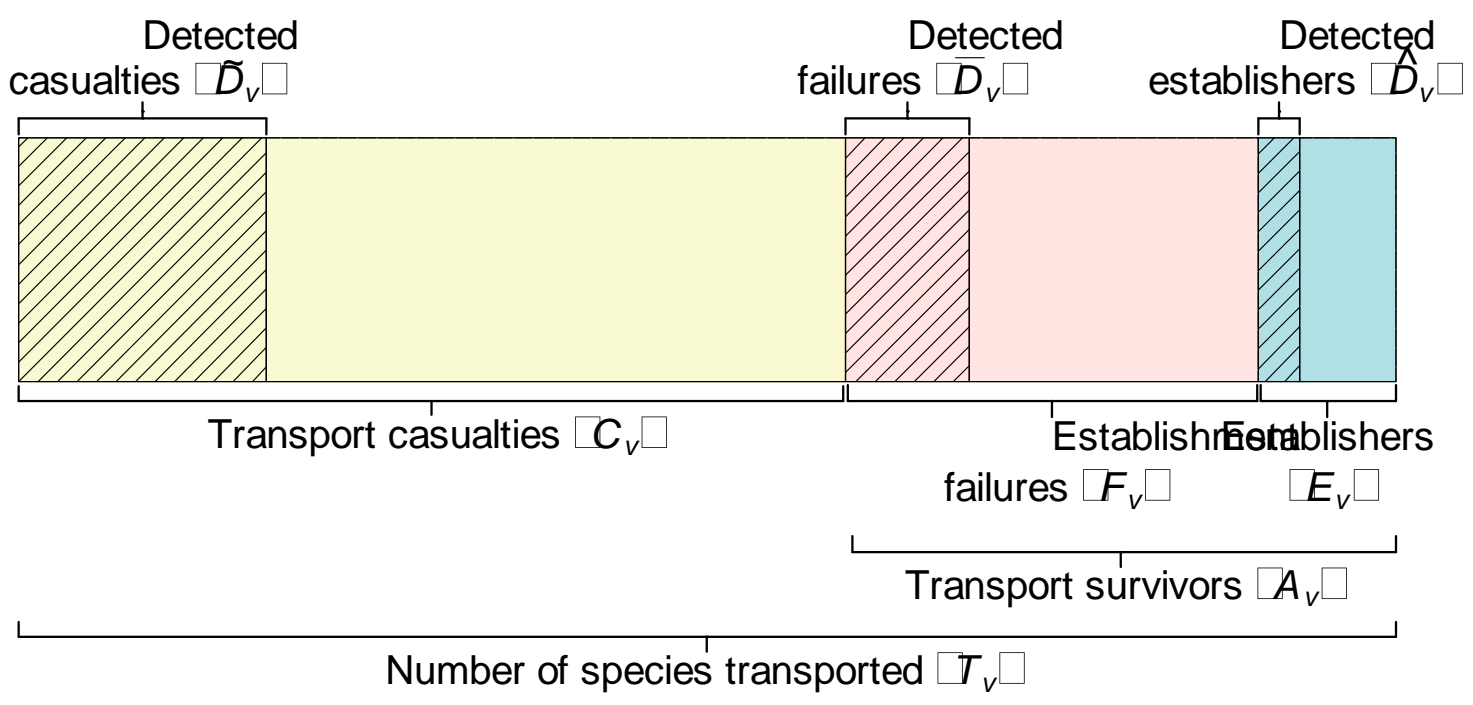

Figure 1. The premise behind the theoretical model used to evaluate four inspection strategies for border control. Of the number of species transported $T_{v}$ along a route $v$ from a donor country to a recipient country, some species will not survive transportation $C_{v}$. Of those species that will survive transportation $A_{v}$, some will fail to establish $F_{v}$ and some will establish $E_{v}$. A proportion of these species will be detected by inspection services (hatched sections)

\subsubsection{Model}

The model components and notation are detailed in Table 1. It was assumed for simplicity that each recipient-donor country combination refers to a route $v$. Let $v \in V$, where $V$ is a set of routes. A number of species $T_{v}$ are transported along each route $v$ (Fig. 1). For each route the number of detections $D_{v}$ is the sum of the number of detected casualties $\widetilde{D}_{v}$, detected failures $\bar{D}_{v}$ and detected establishers $\widehat{D}_{v}$, therefore $D_{v}=\widetilde{D}_{v}+\bar{D}_{v}+\widehat{D}_{v}$. The number of detected casualties $\widetilde{D}_{v}$ is determined by the number of transport casualties $C_{v}$ and the probability of detection $P_{v}$, thus $\widetilde{D}_{v}=C_{v} \times P_{v}$. The number of transport casualties $C_{v}$ is the difference between the number of transported species $T_{v}$ and the number of transport survivors $A_{v}$, therefore we have $C_{v}=T_{v}-A_{v}$. Where the number of transport survivors $A_{v}$ is determined by the number of transported species $T_{v}$ and the probability of surviving transport $\bar{P}_{v}$, thus $A_{V}=T_{v} \times \overline{\bar{P}}_{v}$. The number of detected failures $\bar{D}_{v}$ is determined by the number of establishment failures $F_{v}$ and the probability of detection $P_{v}$, therefore $\bar{D}_{v}=F_{v} \times P_{v}$. The number of establishment failures $F_{v}$ is determined by the number of transport survivors $A_{v}$ and the probability of establishment failure $\bar{P}_{v}$, therefore $F_{v}=A_{v} \times \bar{P}_{v}$. The number of detected establishers $\widehat{D}_{v}$ is determined by the number of establishers $E_{v}$ and the probability 
of detection $P_{v}$, therefore we have $\widehat{D}_{v}=E_{v} \times P_{v}$. The number of establishers $E_{v}$ is the difference between the number of transported species $T_{v}$, the number of transport casualties $C_{v}$ and the number of establishment failures $F_{v}$, thus $E_{v}=T_{v}-\left(C_{v}+F_{v}\right)$. Let $s \in S$, where $S$ is a set of inspection strategies. The total number of detections for each inspection strategy $D_{s}$ is the number of detections across all routes, therefore $D_{s}=\sum_{k \in V} D_{v}$. The total number of detected establishers for each inspection strategy $\widehat{D}_{s}$ is the number of detected establishers $\widehat{D}_{v}$ across all routes, therefore we have $\widehat{D}_{s}=\sum_{k \in V} \widehat{D}_{v}$. Inspection strategy efficacy $E_{s}$ is the percentage of establishers detected across all routes, thus $E_{S}=100\left(\frac{\sum_{k \in V} \widehat{D}_{v}}{\sum_{k \in V} E_{v}}\right)$. For each route, effort per establisher $\hat{I}_{v}$ is the proportion of inspection effort $I_{v}$ allocated to detect each establisher $E_{v}$, therefore $\hat{I}_{v}=\frac{I_{v}}{E_{v}}$. For each inspection strategy, effort $\hat{I}_{s}$ is the average effort per establisher across routes, thus $\hat{I}_{s}=\frac{\sum_{k \in V} \hat{I}_{v}}{n}$ where $n$ is the total number of routes in set $V$. 
Table 1: The components of the theoretical model, the terms used to refer to the components and the notation that represents each component. Notation indexed with $v$ represents per route quantities and that indexed with $s$ represents per inspection strategy quantities. Probabilities are denoted by $P$.

\begin{tabular}{|c|c|c|}
\hline Notation & Term & Model component \\
\hline$T_{v}$ & Number of species transported & Number of species transported along each route \\
\hline$C_{v}$ & Transport casualties & Number of species that do not survive transport along each route \\
\hline$A_{v}$ & Transport survivors & Number of species that survive transport along each route \\
\hline$F_{v}$ & Establishment failures & Number of species transported along each route that survive transport but fail to establish \\
\hline$E_{v}$ & Establishers & Number of species transported along each route that survive transport and that will establish \\
\hline$D_{v}$ & Number of detections & Number of species transported along each route that are detected by inspection services \\
\hline$\widetilde{D}_{v}$ & Detected casualties & Number of detected species transported along each route that do not survive transport \\
\hline $\bar{D}_{v}$ & Detected failures & $\begin{array}{l}\text { Number of detected species transported along each route that survive transport but fail to } \\
\text { establish }\end{array}$ \\
\hline$\widehat{D}_{v}$ & Detected establishers & Number of detected species transported along each route that survive transport and establish \\
\hline$I_{v}$ & Inspection effort & Inspection effort allocated to each route \\
\hline$\hat{I}_{v}$ & Effort per establisher & Inspection effort allocated to each route to detect each establisher \\
\hline$\overline{\bar{P}}_{v}$ & Probability of surviving transport & Probability that a species transported along a route survives transport \\
\hline $\bar{P}_{v}$ & Probability of establishment failure & Probability that a species transported along a route fails to establish \\
\hline$P_{v}$ & Probability of detection & Probability that a species transported along a route is detected \\
\hline$D_{s}$ & Total number of detections & Number of species detected for each strategy \\
\hline$\widehat{D}_{s}$ & Total number of detected establishers & Number of species detected for each strategy that will survive transport and establish \\
\hline$E_{S}$ & Strategy efficacy & The efficacy of each strategy \\
\hline$\hat{I}_{s}$ & Effort & Average inspection effort allocated in each strategy to detect each establisher \\
\hline
\end{tabular}


1.4.3. Model implementation and parameterisation

Consider that recipient country $R$ imports commodities from a set of donor countries $G$ and let $g \in G$. The theoretical model can be used to evaluate the four inspection strategies for countries $G$ which differ with regards to their climatic similarity to country $R$ and in the number of species transported to country $R$. Therefore each route has different combinations of climatic similarity and number of species transported. In the model, species are transported to country $R$ through four routes, each representing an extreme combination of climatic similarity and number of transported species. We define the set of routes $V$ to be the following:

$v_{1}$ : High number of transported species and $g_{1}$ is climatically similar to $R$.

$v_{2}$ : Low number of transported species and $g_{2}$ is climatically similar to $R$.

$v_{3}$ : High number of transported species and $g_{3}$ is not climatically similar to $R$.

$v_{4}$ : Low number of transported species and $g_{4}$ is not climatically similar to $R$.

It must be noted that this scenario represents a snapshot in time, and that the number of species transported along each route and the climatic similarity of the recipient and donor countries will vary temporally. However if updated regularly, inspection strategies should keep up with these variations.

We define the set of inspection strategies $S$ to be the following:

$s_{1}$ : Border control with no prioritisation. Routes are inspected equally.

$s_{2}$ : Border control with prioritisation based on colonisation pressure, measured as the number of species transported along a route $T_{v}$. Routes with a high $T_{v}$ will be an inspection priority.

$s_{3}$ : Border control with prioritisation based on the likelihood of establishment, measured as the climatic similarity between $R$ and $g$. Routes from countries $G$ that are climatically similar to $R$ will be an inspection priority.

$s_{4}$ : Border control with prioritisation based on establishment debt, measured as the number of species transported along a route that will establish (i.e. $E_{v}$ ). Routes from countries $G$ that are climatically similar to $R$ and that have a high $T_{v}$ will be an inspection priority.

The model was parameterised using a combination of estimates from published works and assumptions (see Tables 2, 3 and 4 for parameters). As data to parameterise the model 
were available at a species level, species was used as the unit of measurement. In a real world situation individuals of species would be transported, introduced and detected in inspections. However, species or individuals could be used as this model's unit of measurement as it is unlikely that the unit utilised would influence the overall results. The likelihood that an organism survives transportation is highly variable and is influenced by numerous interacting factors (e.g. the type of organism and vector, see Briski et al., 2014). As this work was not vector- or species-specific, for simplicity it was assumed that the probability of surviving transport $\overline{\bar{P}}_{v}$ is constant for all routes (Table 2) and estimates for this parameter were taken from Stanaway et al. (2001). Estimates of the probability of establishment failure $\bar{P}_{v}$ were based on the assumption that of the total number of species introduced to the recipient country the proportion that are establishment failures will be constant (0.98 based on estimates from di Castri, 1989). However, the contribution that species transported along the different routes make to this proportion will vary based on the climatic similarity between the recipient and donor countries (Table 2). In other words, the proportion of species that are establishment failures will be higher for routes that connect climatically dissimilar countries, than for routes that connect climatically similar countries (Table 2). Similarly estimates of the probability of detection $P_{v}$ were based on the assumption that total inspection effort is limited and constant, and thus of the total number of species introduced to the recipient country the proportion that are detected casualties, failures or establishers is constant (0.24 based on estimates from Work et al., 2005 on nonrefrigerated maritime cargo). However based on the inspection strategy, the proportion of inspection effort allocated to each route will vary and as a consequence the contribution species transported along different routes make to this proportion will also vary (Tables 3 and 4). In other words, the probability of detection will be higher for routes that are an inspection priority (i.e. higher proportion of inspection effort) than for routes that have not been prioritised (Table 4). The assumptions made in this model may not hold in all instances and a variety of potentially important factors were not considered. For example, although it has been shown that observed alien species richness increases linearly with an increase in inspection effort (Work et al., 2005), various factors (e.g. packaging type) may affect the ease of inspections and consequently the likelihood of detecting an organism (Bacon et al., 2012). Despite this, this simple model served the purpose of the work. 
Table 2: Parameter values for the theoretical model used to evaluate four inspection strategies that aim to prevent the introduction of species that are transported along four routes to recipient country $R$. For all inspection strategies the probability that introduced species will fail to establish is constant at $\mathbf{0 . 9 8}$, and is based on an estimate from di Castri (1989).

\begin{tabular}{llrrr}
\hline \multicolumn{1}{c}{ Parameter } & \multicolumn{3}{c}{ Route } & \\
& $v_{1}$ & $v_{2}$ & $v_{3}$ & $v_{4}$ \\
\hline Number of species transported $\left(T_{v}\right)$ & $100^{\mathrm{a}}$ & $20^{\mathrm{a}}$ & $100^{\mathrm{a}}$ & $20^{\mathrm{a}}$ \\
Probability of surviving transport $\left(\overline{\bar{P}}_{v}\right)$ & $0.19^{\mathrm{b}}$ & $0.19^{\mathrm{b}}$ & $0.19^{\mathrm{b}}$ & $0.19^{\mathrm{b}}$ \\
Probability of establishment failure $\left(\bar{P}_{v}\right)$ & $0.97^{\mathrm{c}}$ & $0.97^{\mathrm{c}}$ & $0.99^{\mathrm{c}}$ & $0.99^{\mathrm{c}}$ \\
\hline a Own assumption & & & & \\
'Based on Stanaway et al. (2001) & & & &
\end{tabular}

Table 3: Parameter values for the proportion of inspection effort $I_{v}$ allocated under four inspection strategies that aim to prevent the introduction of species transported along four routes to recipient country $R$. Total inspection effort for all inspection strategies is constant.

\begin{tabular}{lcccc}
\hline \multicolumn{1}{c}{ Inspection strategy } & $v_{1}$ & $v_{2}$ & $v_{3}$ & $v_{4}$ \\
\hline No priorities $\left(s_{1}\right)$ & 0.25 & 0.25 & 0.25 & 0.25 \\
Colonisation pressure $\left(s_{2}\right)$ & 0.42 & 0.08 & 0.42 & 0.08 \\
Likelihood of establishment $\left(s_{3}\right)$ & 0.42 & 0.42 & 0.08 & 0.08 \\
Establishment debt $\left(s_{4}\right)$ & 0.55 & 0.22 & 0.22 & 0.01 \\
\hline
\end{tabular}

Table 4: Parameter values for the probability that species transported along four routes to recipient country $R$ will be detected $P_{v}$ under four inspection strategies. The probability of detection for all inspection strategies is constant at 0.24 , and is based on an estimate from Work et al. (2005) for non-refrigerated maritime cargo.

\begin{tabular}{lcccc}
\hline \multicolumn{1}{c}{ Inspection strategy } & \multicolumn{3}{c}{ Route } \\
& $v_{1}$ & $v_{2}$ & $v_{3}$ & $v_{4}$ \\
\hline No priorities $\left(s_{1}\right)$ & 0.24 & 0.24 & 0.24 & 0.24 \\
Colonisation pressure $\left(s_{2}\right)$ & 0.40 & 0.08 & 0.40 & 0.08 \\
Likelihood of establishment $\left(s_{3}\right)$ & 0.40 & 0.40 & 0.08 & 0.08 \\
Establishment debt $\left(s_{4}\right)$ & 0.53 & 0.21 & 0.21 & 0.01 \\
\hline
\end{tabular}




\section{References}

Bacon, S.J., Bacher, S., Aebi, A., 2012. Gaps in border controls are related to quarantine alien insect invasions in Europe. PLoS One 7, e47689.

Barry, S.C., Hayes, K.R., Hewitt, C.L., Behrens, H.L., Dragsund, E., Bakke, S.M., 2008. Ballast water risk assessment: principles, processes, and methods. ICES J. Mar. Sci. 65, 121-131.

Bivand, R., Lewin-Koh, N., 2013. maptools: Tools for reading and handling spatial objects [WWW Document]. URL http://cran.r-project.org/package=maptools (accessed 11.11.13).

Blackburn, T.M., Pyšek, P., Bacher, S., Carlton, J.T., Duncan, R.P., Jarošík, V., Wilson, J.R.U., Richardson, D.M., 2011. A proposed unified framework for biological invasions. Trends Ecol. Evol. 26, 333-339.

Bradie, J., Pietrobon, A., Leung, B., 2015. Beyond species-specific assessments: an analysis and validation of environmental distance metrics for non-indigenous species risk assessment. Biol. Invasions 17, 3455-3465.

Briski, E., Chan, F.T., Maclsaac, H.J., Bailey, S.A., 2014. A conceptual model of community dynamics during the transport stage of the invasion process: a case study of ships' ballast. Divers. Distrib. 20, 236-244.

Busby, J.R., 1991. BIOCLIM - a bioclimate analysis and prediction system, in: Margules, C.R., Austin, M.P. (Eds.), Nature Conservation: Cost Effective Biological Surveys and Data Analysis. CSIRO, Melbourne, pp. 64-68.

Derraik, J.G.B., 2004. Exotic mosquitoes in New Zealand: a review of species intercepted, their pathways and ports of entry. Aust. N. Z. J. Public Health 28, 433-444.

di Castri, F., 1989. History of biological invasions with special emphasis on the old world, in: Drake, J.A. (Ed.), Biological Invasions: A Global Perspective. John Wiley \& Sons Ltd, Chichester, pp. 1-30.

Faulkner, K.T., Robertson, M.P., Rouget, M., Wilson, J.R.U., 2014. A simple, rapid methodology for developing invasive species watch lists. Biol. Conserv. 179, 25-32.

Keller, R.P., Drake, J.M., Drew, M.B., Lodge, D.M., 2011. Linking environmental conditions and ship movements to estimate invasive species transport across the global shipping network. Divers. Distrib. 17, 93-102.

Lockwood, J.L., Cassey, P., Blackburn, T.M., 2009. The more you introduce the more you get: the role of colonization pressure and propagule pressure in invasion ecology. Divers. Distrib. 15, 904-910.

New, M., Lister, D., Hulme, M., Makin, I., 2002. A high-resolution data set of surface climate over global land areas. Clim. Res. 21, 1-25.

Olson, D.M., Dinerstein, E., Wikramanayake, E.D., Burgess, N.D., Powell, G.V.N., Underwood, E.C., D'Amico, J.A., Itoua, I., Strand, H.E., Morrison, J.C., Loucks, C.J., Allnutt, T.F., Ricketts, T.H., Kura, Y., Lamoreux, J.F., Wettengel, W.W., Hedao, P., 
Kassem, K.R., 2001. Terrestrial ecoregions of the world: a new map of life on earth. Bioscience 51, 933-938.

R Core Team, 2013. R: a language and environment for statistical computing [WWW Document]. URL http://www.r-project.org/ (accessed 11.11.13).

Rouget, M., Robertson, M.P., Wilson, J.R.U., Hui, C., Essl, F., Renteria, J.L., Richardson, D.M., 2016. Invasion debt - quantifying future biological invasions. Divers. Distrib. 22, 445-456.

Stanaway, M.A., Zalucki, M.P., Gillespie, P.S., Rodriguez, C.M., Maynard, G.V., 2001. Pest risk assessment of insects in sea cargo containers. Aust. J. Entomol. 40, 180-192.

Tatem, A.J., Hay, S.I., Rogers, D.J., 2006a. Global traffic and disease vector dispersal. Proc. Natl. Acad. Sci. U. S. A. 103, 6242-6247.

Work, T.T., McCullough, D.G., Cavey, J.F., Komsa, R., 2005. Arrival rate of nonindigenous insect species into the United States through foreign trade. Biol. Invasions 7, 323-332. 


\section{Supplementary Materials}

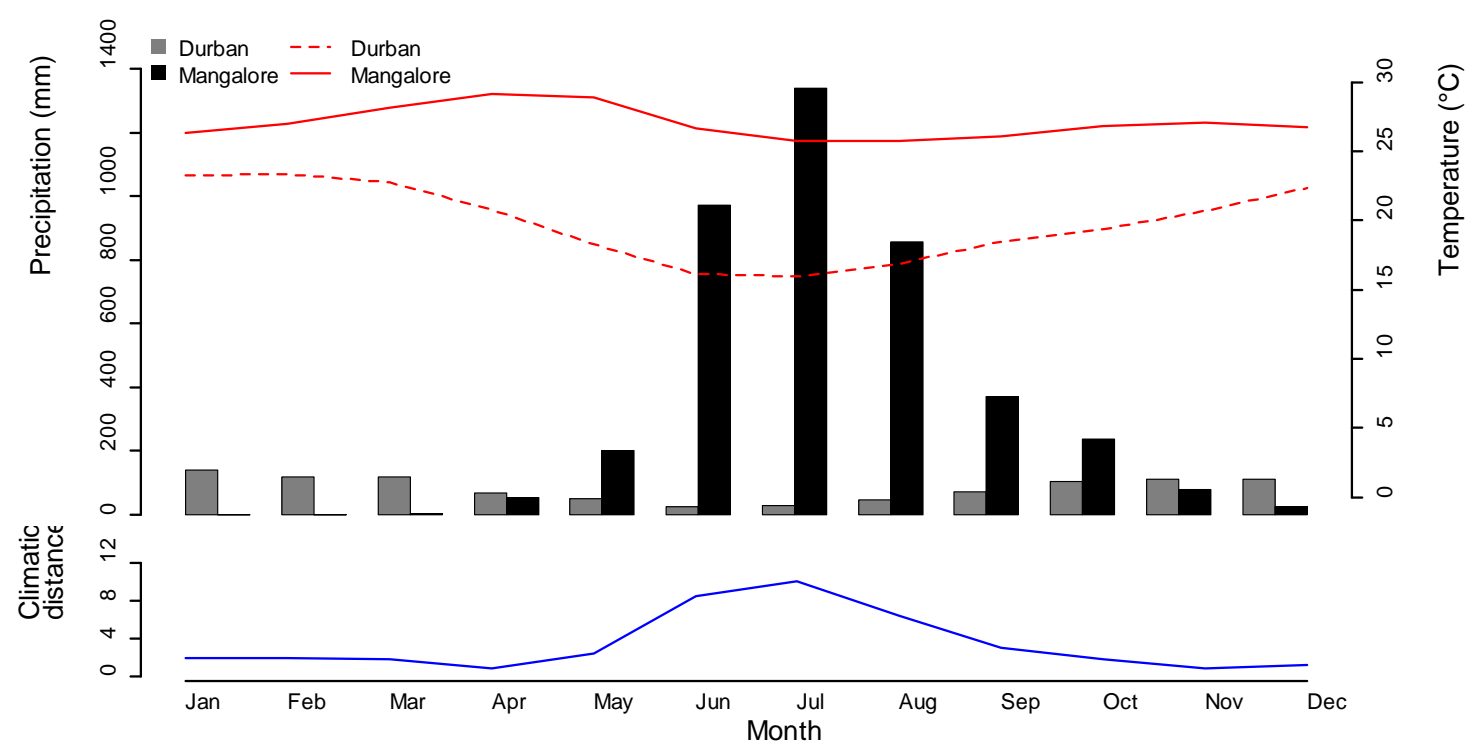

Figure S1. Monthly precipitation and temperature data for Mangalore (India) and Durban (South Africa), and the monthly climatic distance (measured using Euclidean distance) between the two cities.

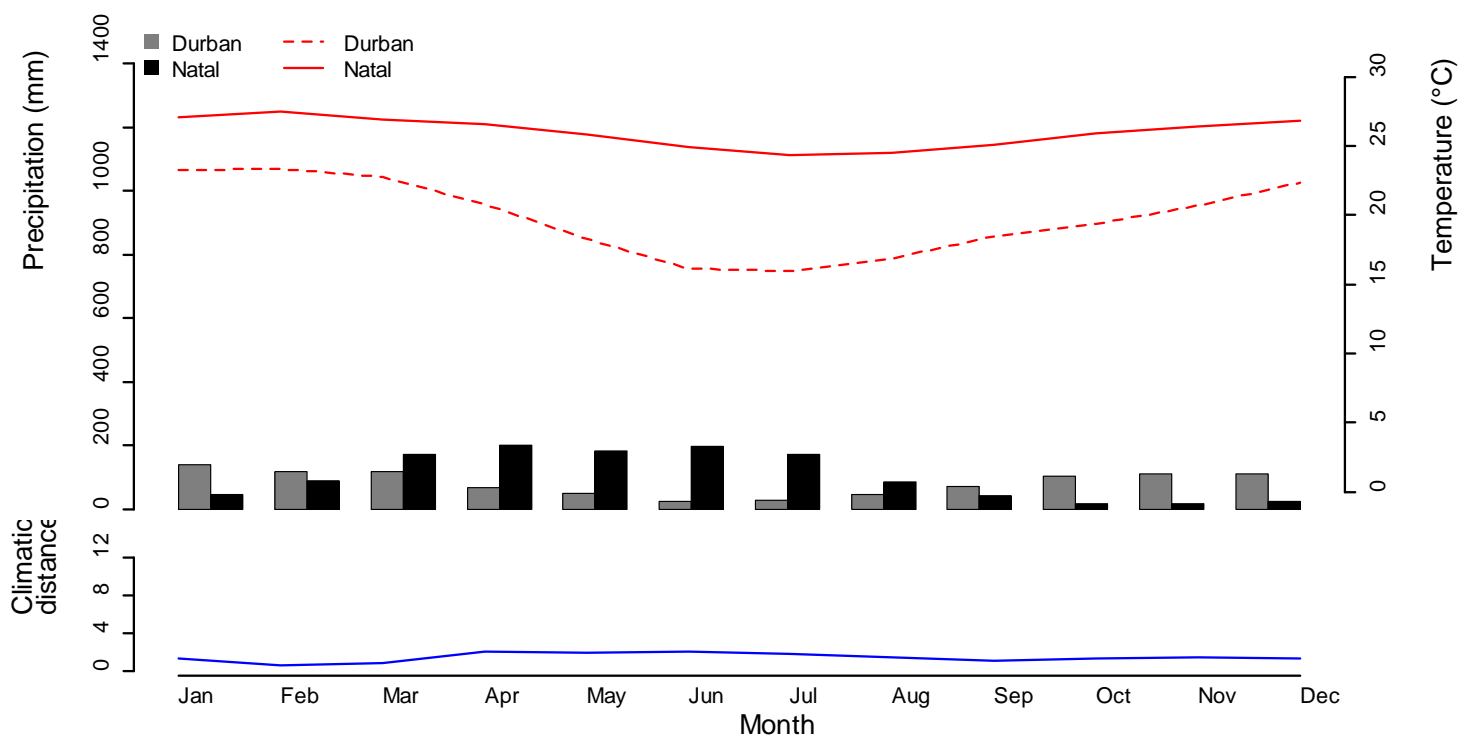

Figure S2. Monthly precipitation and temperature data for Natal (Brazil) and Durban (South Africa), and the monthly climatic distance (measured using Euclidean distance) between the two cities. 


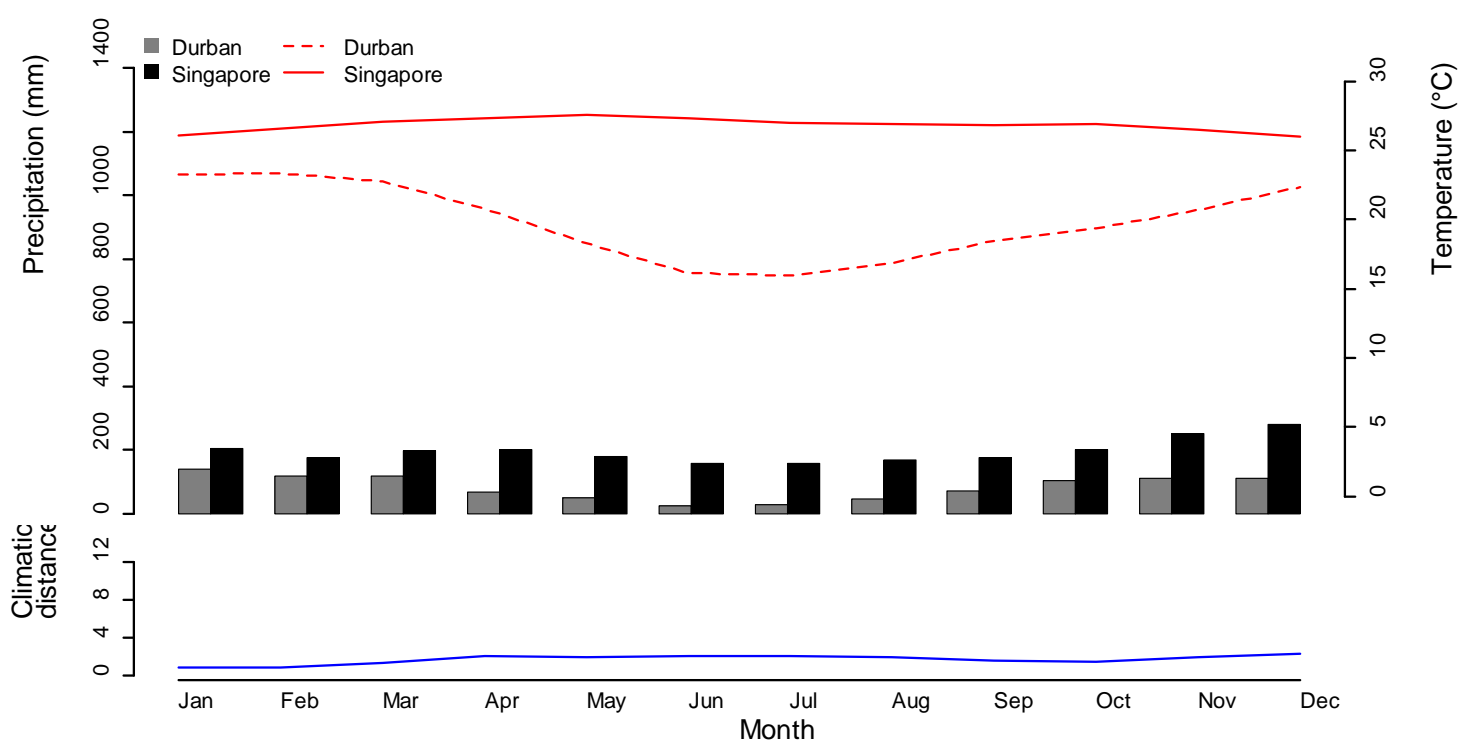

Figure S3. Monthly precipitation and temperature data for Singapore and Durban (South Africa), and the monthly climatic distance (measured using Euclidean distance) between the two cities.

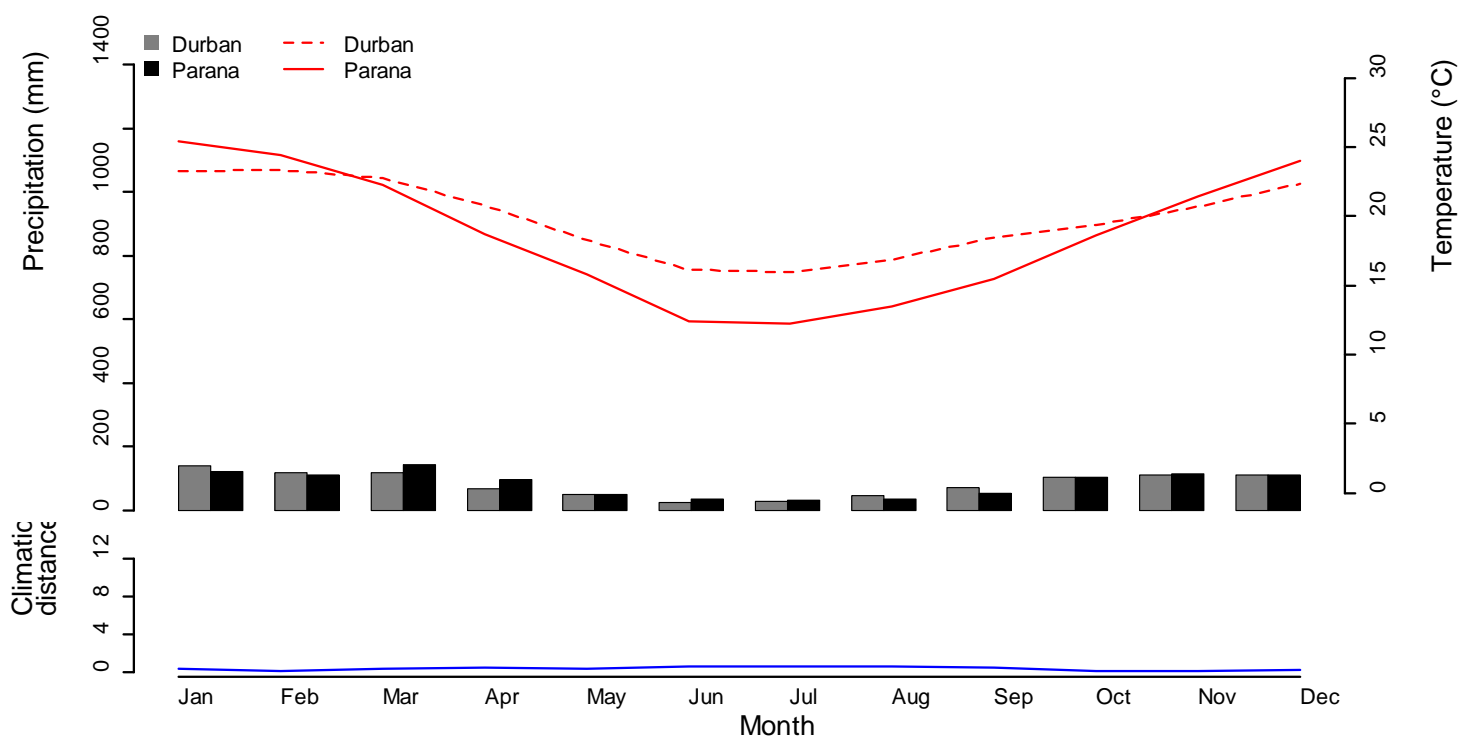

Figure S4. Monthly precipitation and temperature data for Parana (Argentina) and Durban (South Africa), and the monthly climatic distance (measured using Euclidean distance) between the two cities. 


\section{Supplementary Materials}

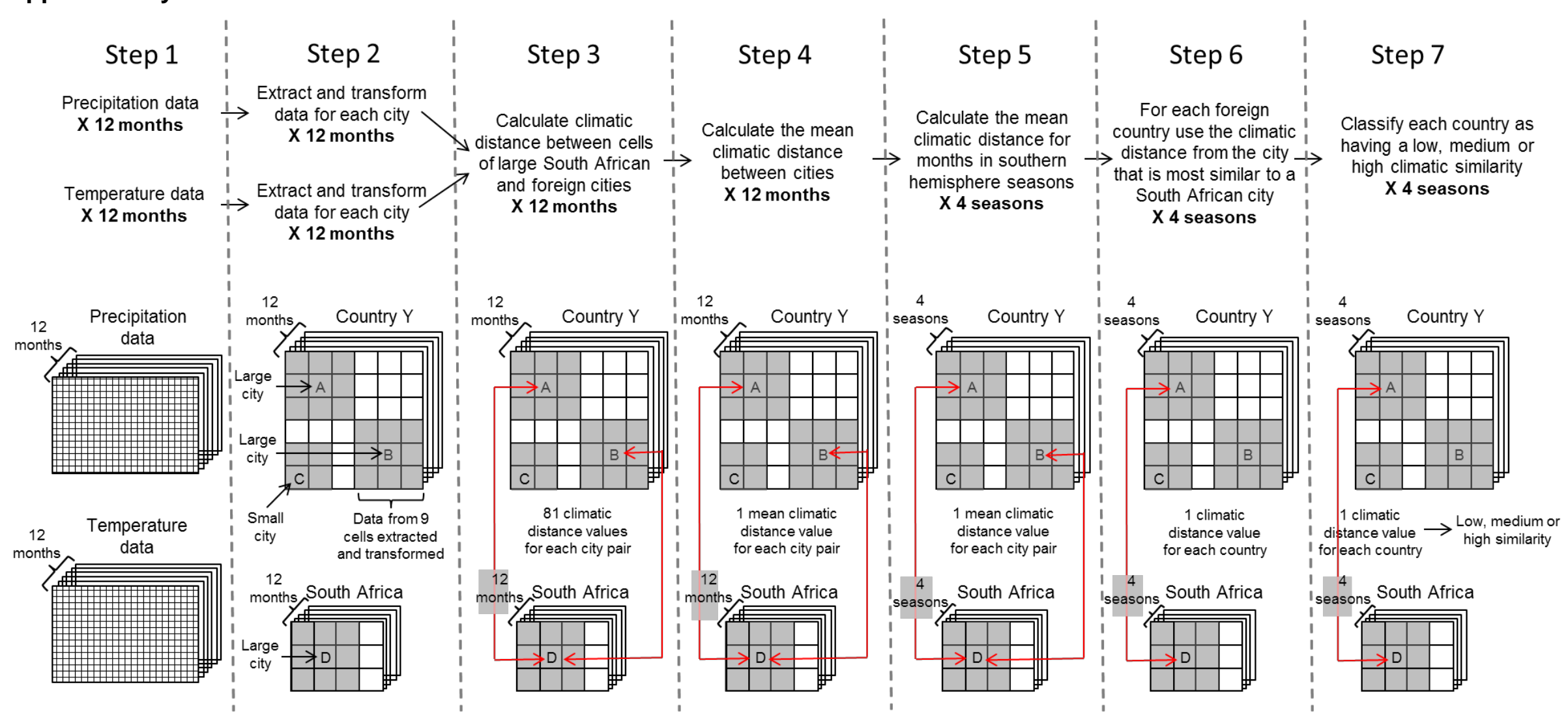

Figure S5. Schematic diagram demonstrating the steps followed in the point-based climate matching technique: (1) obtain gridded monthly mean temperature and precipitation data; (2) from the monthly climate data, extract and transform the data from the cell associated with each city, as well as from all adjacent cells; (3) for each month, calculate the climatic distance (using Euclidean distance) between the cells associated with large South African cities and large foreign cities (populations of $\geq 100$ 000); (4) for each month, calculate the mean climatic distance for each city comparison; (5) obtain seasonal results for each city comparison by taking the mean of the climatic distance results for months that fall into southern hemisphere seasons; (6) for each season, identify the large city in each foreign country that has the lowest climatic distance to a large South African city; (7) using the climatic distance results of cities identified in step 6, for each season classify each country as having a low (values $\geq 50^{\text {th }}$ percentile), medium (values $\leq 50^{\text {th }}$ percentile) or high (values $\leq 25^{\text {th }}$ percentile) climatic similarity to South Africa. 


\section{Supplementary Materials}

Southern hemisphere summer

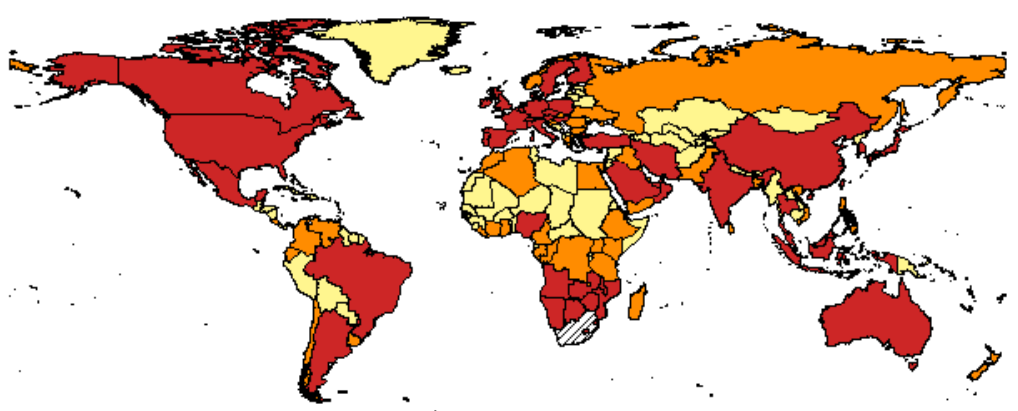

Southern hemisphere winter

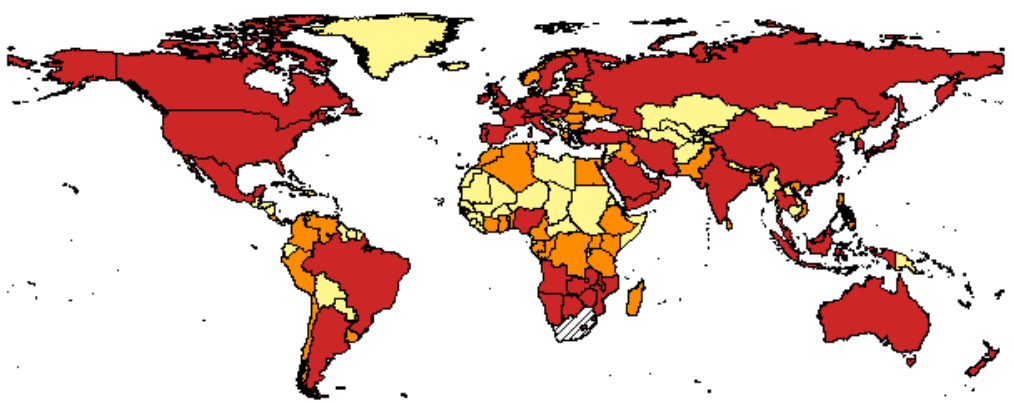

Southern hemisphere autumn

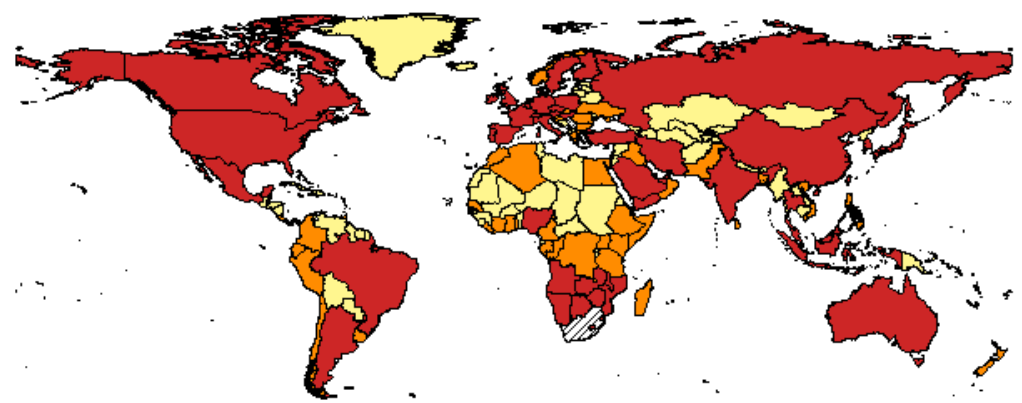

Southern hemisphere spring

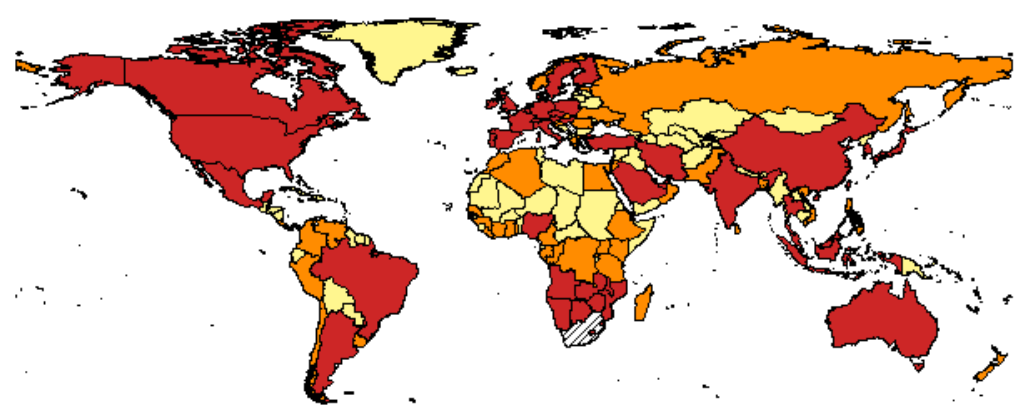

Figure S6. Seasonal variation (based on southern hemisphere seasons) in the countries that pose a $\square$ low, $\square$ medium or $\square$ high colonisation pressure to South Africa (hatched). 
Southern hemisphere summer

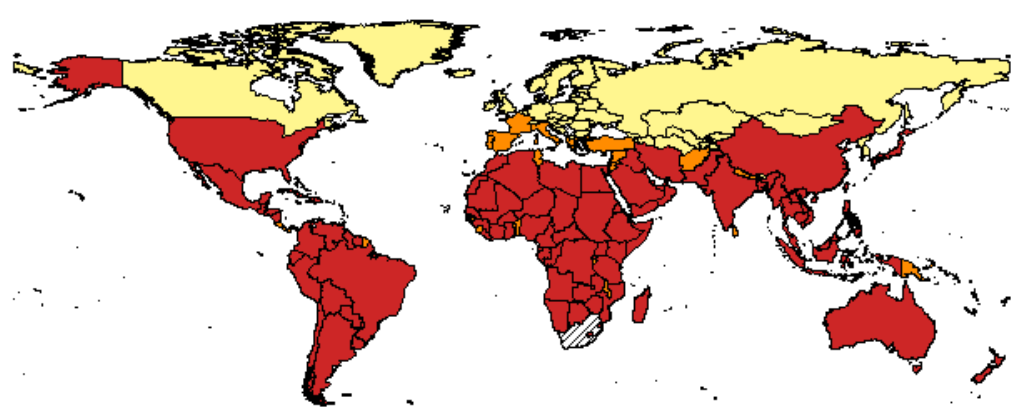

Southern hemisphere winter

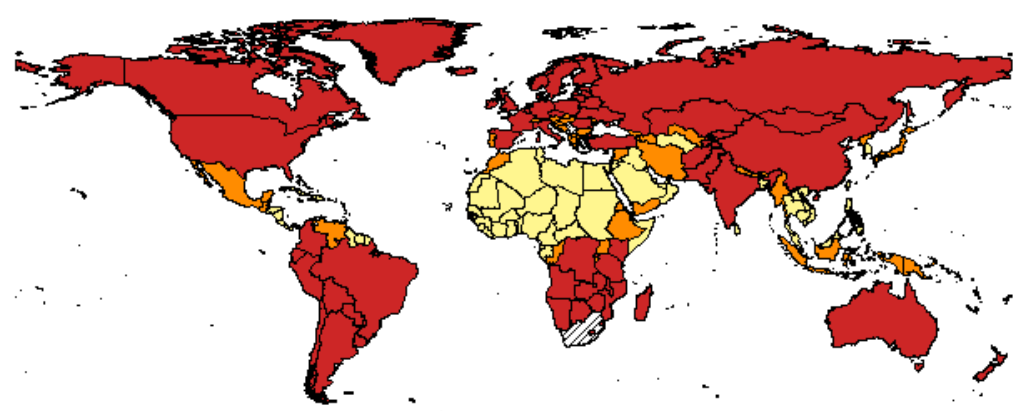

Southern hemisphere autumn

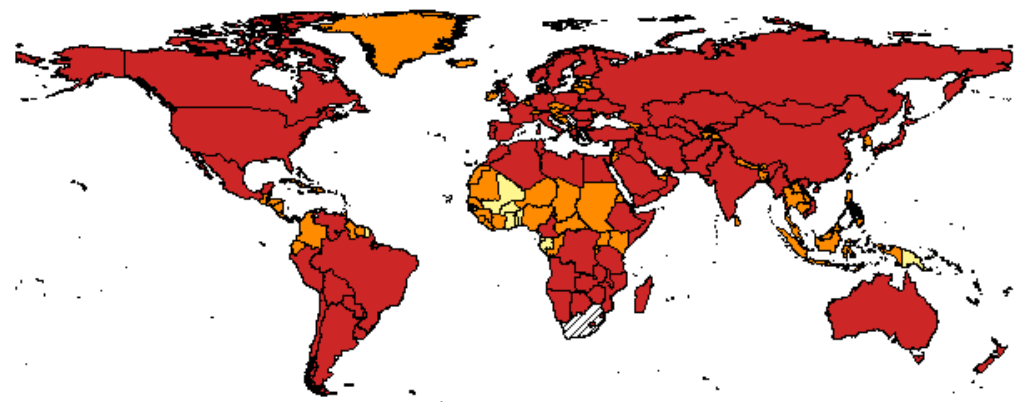

Southern hemisphere spring

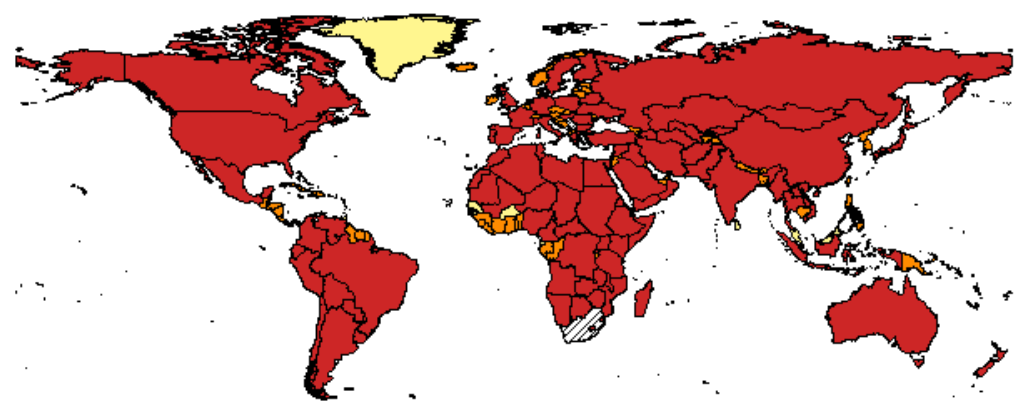

Figure S7. Seasonal variation (based on southern hemisphere seasons) in the countries from which introduced organisms have a $\square$ low, $\square$ medium or $\square$ high likelihood of establishing in South Africa (hatched). 
Southern hemisphere summer

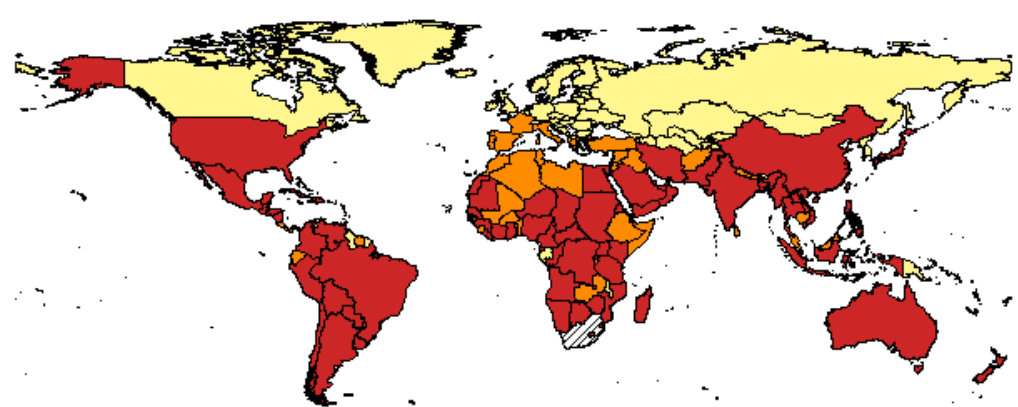

Southern hemisphere winter

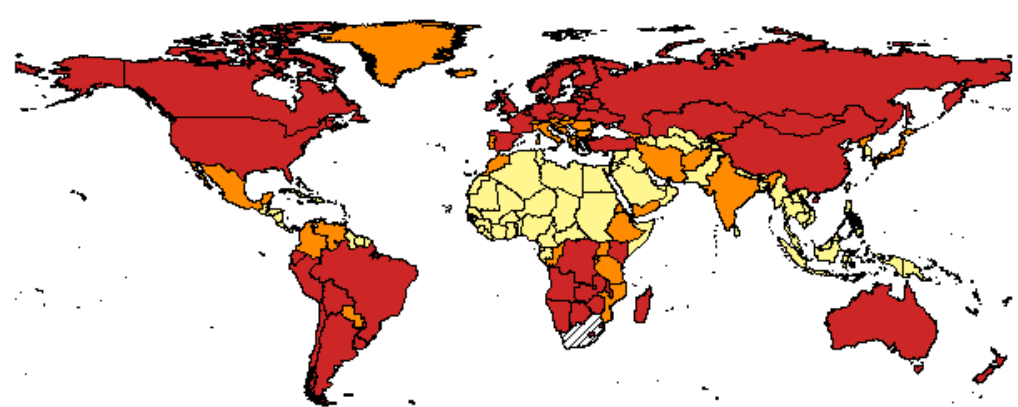

Southern hemisphere autumn

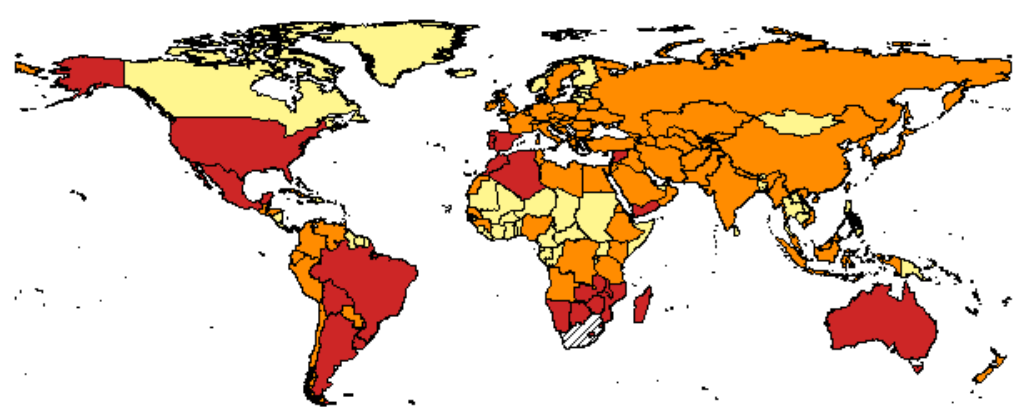

Southern hemisphere spring

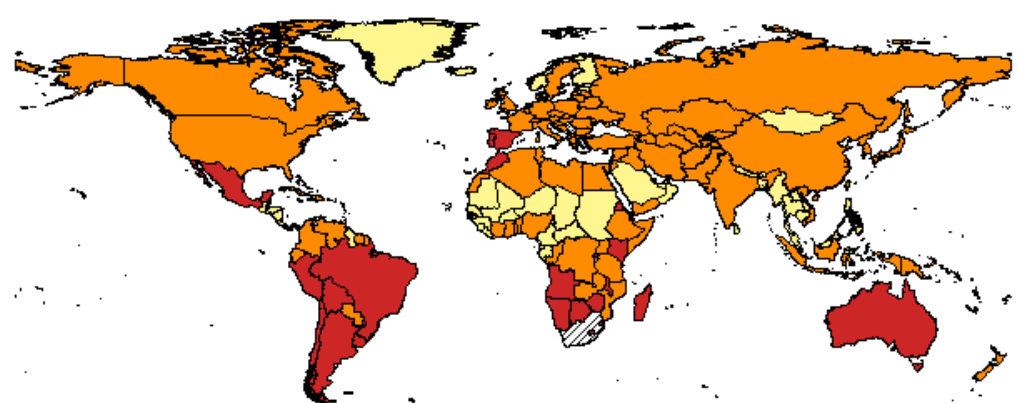

Figure S8. Seasonal variation (based on southern hemisphere seasons) in the countries that have a $\square$ low, $\square$ medium or $\square$ high climatic similarity to South Africa (hatched). Climatic similarity was determined using a point-based method. 
Southern hemisphere summer

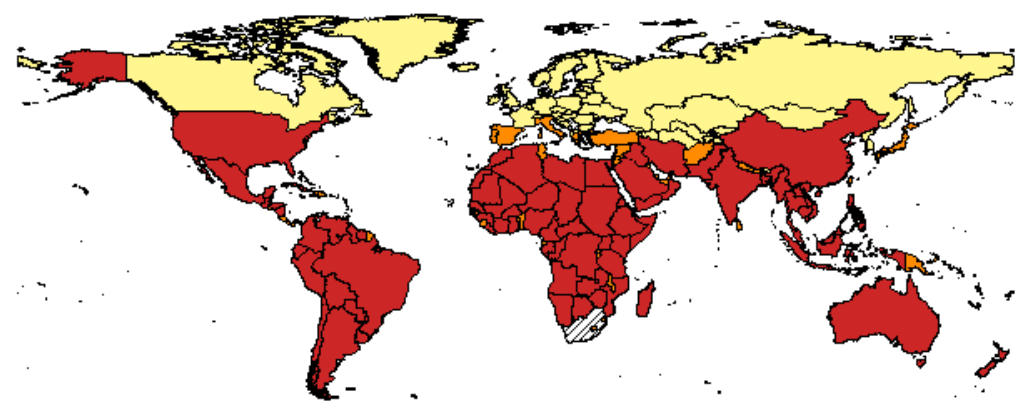

Southern hemisphere winter

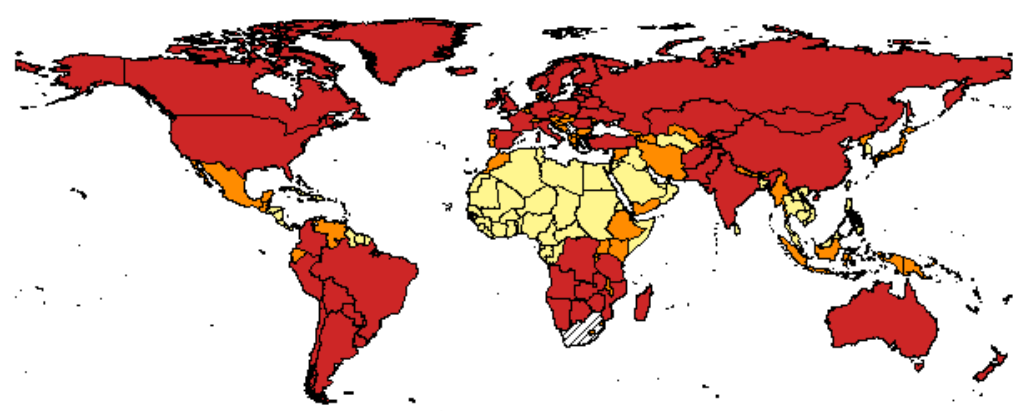

Southern hemisphere autumn

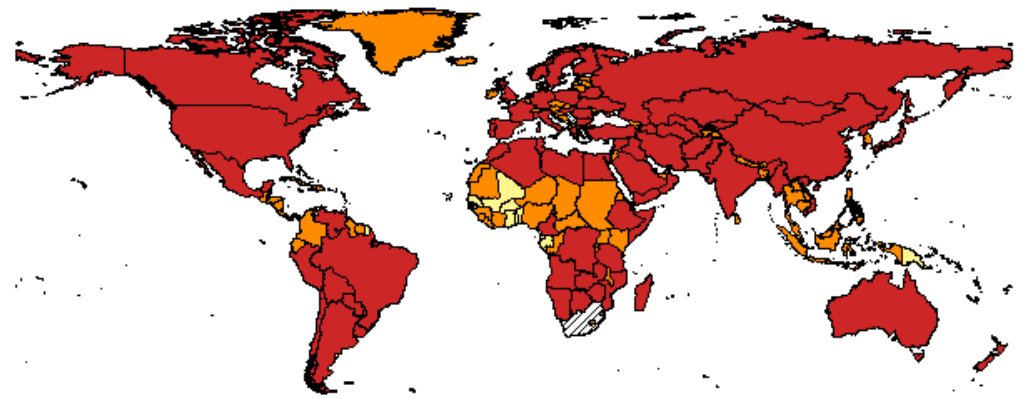

Southern hemisphere spring

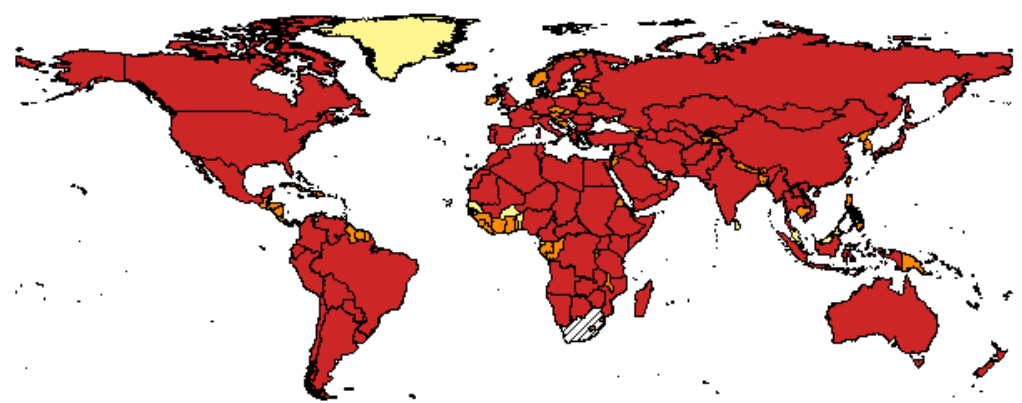

Figure S9. Seasonal variation (based on southern hemisphere seasons) in the countries that have a $\square$ low, $\square$ medium or $\square$ high climatic similarity to South Africa (hatched). Climatic similarity was determined using a grid-based method. 


\section{Supplementary Materials}

Table S1. Results of the theoretical model testing the four inspection strategies for border control. The total number of detections for each strategy is the number of species detected $D_{v}$ by border control across all routes. The number of detected establishers for each strategy is the number of establishers that are detected by border control across all routes. Strategy efficacy $\left(E_{s}\right)$ is the percentage of establishers $\left(E_{v}\right)$ detected by border control across all routes. Effort is the average inspection effort allocated by border control across all routes to detect each establisher

\begin{tabular}{|c|c|c|c|c|c|c|c|}
\hline Inspection strategy & Route & $\begin{array}{c}\text { Number of species } \\
\text { transported } \\
\left(T_{v}\right)\end{array}$ & $\begin{array}{l}\text { Climatic } \\
\text { similarity }\end{array}$ & $\begin{array}{c}\text { Total number of } \\
\text { detections } \\
\left(D_{v}\right) \\
\end{array}$ & $\begin{array}{l}\text { Establishers } \\
\qquad\left(E_{v}\right)\end{array}$ & $\begin{array}{c}\text { Detected } \\
\text { establishers } \\
\left(\widehat{D}_{v}\right) \\
\end{array}$ & $\begin{array}{c}\text { Effort per } \\
\text { establisher } \\
\left(\hat{I}_{v}\right)\end{array}$ \\
\hline \multirow[t]{4}{*}{ No priorities $\left(s_{1}\right)$} & $v_{1}$ & High & High & 24.00 & 0.57 & 0.14 & 0.44 \\
\hline & $v_{2}$ & Low & High & 4.80 & 0.11 & 0.03 & 2.19 \\
\hline & $v_{3}$ & High & Low & 24.00 & 0.19 & 0.05 & 1.32 \\
\hline & $v_{4}$ & Low & Low & 4.80 & 0.04 & 0.01 & 6.58 \\
\hline \multirow[t]{4}{*}{ Colonisation pressure $\left(s_{2}\right)$} & $v_{1}$ & High & High & 40.00 & 0.57 & 0.23 & 0.73 \\
\hline & $v_{2}$ & Low & High & 1.60 & 0.11 & 0.01 & 0.73 \\
\hline & $v_{3}$ & High & Low & 40.00 & 0.19 & 0.08 & 2.19 \\
\hline & $v_{4}$ & Low & Low & 1.60 & 0.04 & 0.00 & 2.19 \\
\hline \multirow[t]{4}{*}{ Likelihood of establishment $\left(s_{3}\right)$} & $v_{1}$ & High & High & 40.00 & 0.57 & 0.23 & 0.73 \\
\hline & $v_{2}$ & Low & High & 8.00 & 0.11 & 0.05 & 3.65 \\
\hline & $v_{3}$ & High & Low & 8.00 & 0.19 & 0.02 & 0.44 \\
\hline & $v_{4}$ & Low & Low & 1.60 & 0.04 & 0.00 & 2.19 \\
\hline \multirow[t]{4}{*}{ Establishment debt $\left(s_{4}\right)$} & $v_{1}$ & High & High & 53.00 & 0.57 & 0.30 & 0.97 \\
\hline & $v_{2}$ & Low & High & 4.20 & 0.11 & 0.02 & 1.92 \\
\hline & $v_{3}$ & High & Low & 21.00 & 0.19 & 0.04 & 1.15 \\
\hline & $v_{4}$ & Low & Low & 0.20 & 0.04 & 0.00 & 0.27 \\
\hline
\end{tabular}

